\title{
Application of Zebrafish Model in the Suppression of Drug-Induced Cardiac Hypertrophy by Traditional Indian Medicine Yogendra Ras
}

\author{
Acharya Balkrishna ${ }^{1,2}$, Yashika Rustagi ${ }^{1}$, Kunal Bhattacharya ${ }^{1, *}$ and Anurag Varshney $1,2, *$ (D) \\ 1 Drug Discovery and Development Division, Patanjali Research Institute, Haridwar 249 401, India \\ 2 Department of Allied and Applied Sciences, University of Patanjali, Patanjali Yog Peeth, \\ Haridwar 249 401, India \\ * Correspondence: kunalbhattacharya@prft.co.in (K.B.); anurag@prft.co.in (A.V.); \\ Tel.: +91-1334-244107 (K.B. \& A.V.); Fax: +91-1334-244805 (K.B. \& A.V.)
}

Received: 29 February 2020; Accepted: 6 April 2020; Published: 13 April 2020

\begin{abstract}
Zebrafish is an elegant vertebrate employed to model the pathological etiologies of human maladies such as cardiac diseases. Persistent physiological stresses can induce abnormalities in heart functions such as cardiac hypertrophy $(\mathrm{CH})$, which can lead to morbidity and mortality. In the present study, using zebrafish as a study model, efficacy of the traditional Indian Ayurveda medicine "Yogendra Ras" (YDR) was validated in ameliorating drug-induced cardiac hypertrophy. YDR was prepared using traditionally described methods and composed of nano- and micron-sized metal particles. Elemental composition analysis of YDR showed the presence of mainly $\mathrm{Au}$, $\mathrm{Sn}$, and $\mathrm{Hg}$. Cardiac hypertrophy was induced in the zebrafish following a pretreatment with erythromycin (ERY), and the onset and reconciliation of disease by YDR were determined using a treadmill electrocardiogram, heart anatomy analysis, C-reactive protein release, and platelet aggregation time-analysis. YDR treatment of $\mathrm{CH}$-induced zebrafish showed comparable results with the Standard-of-care drug, verapamil, tested in parallel. Under in-vitro conditions, treatment of isoproterenol (ISP)-stimulated murine cardiomyocytes (H9C2) with YDR resulted in the suppression of drug-stimulated biomarkers of oxidative stress: COX-2, NOX-2, NOX-4, ANF, troponin-I, -T, and cardiolipin. Taken together, zebrafish showed a strong disposition as a model for studying the efficacy of Ayurvedic medicines towards drug-induced cardiopathies. YDR provided strong evidence for its capability in modulating drug-induced $\mathrm{CH}$ through the restoration of redox homeostasis and exhibited potential as a viable complementary therapy.
\end{abstract}

Keywords: Ayurveda; cardiac hypertrophy; zebrafish model; H9C2; erythromycin; isoproterenol; oxidative stress; Yogendra Ras; biomarkers

\section{Introduction}

The zebrafish (Danio rerio) has emerged as a useful tool in the study of human diseases, recapitulating some or all of the observed pathologies. Through whole-genome mapping, D. rerio has been replacing small animal models in understanding disease modalities and their conserved molecular pathways. D. rerio has also been used as a model for studying cardiac stress and diseases using electrocardiograms (ECGs) and biochemical parameters, since they closely resemble those of humans [1-3]. The heart is a major organ involved in the perfusion of blood and oxygen demands to the distal organs [4]. During cardiac failures, it is unable to adequately pump blood to the organs in response to systemic demands and can lead to mortality [5]. Cardiac hypertrophy $(\mathrm{CH})$ is induced through physical and pathological stress, which produces stimuli for the cardiomyocytes to grow 
in length and width. Physiologically, this leads to an increase in the cardiac pump function while decreasing ventricular wall tension and in turn inducing compensated $\mathrm{CH}$. It is also accompanied by an increase in the left ventricular wall thickness, as a response to the reduction of systolic and diastolic stress on the left cardiac wall. Long-term persistence of $\mathrm{CH}$ could lead to heart failure, arrhythmia, and sudden death [6].

Erythromycin (ERY) is a macrolide antibiotic generally associated with gastrointestinal distress. ERY is also a motilin receptor agonist that reduces the G-coupled receptor-stimulated contractions in the smooth muscle. Studies have shown that oral treatment of patients with ERY followed by its metabolism by cytochrome P4503A (CYP3A) leads to an increase of the drug concentration in the blood plasma, consequently leading to the development of cardiac arrhythmia and torsade de pointes (TdP) by blocking human-ether-a-go-go gene (hERG) and prolonging QTc intervals [7]. In D. rerio, ERY has been successfully shown to be an inducing agent of $\mathrm{CH}$ and $\mathrm{TdP}[8,9]$. Isoproterenol (ISP) is a synthetic catecholamine and stimulator (agonist) for $\beta$-adrenergic receptors $(\beta-A R)$ that exerts its effect on the cardiac tissues. The sustained activation of the $\beta$-AR and an increase in the cytosolic $\mathrm{Ca}^{2+}$ levels can lead to the induction of $\mathrm{CH}$, producing the hypertrophic phenotype $[10,11]$. Cardiomyocytes are mainly composed of mitochondria due to high energy requirements and generate reactive oxygen species (ROS) as a by-product of oxidative phosphorylation [12,13]. Therefore, the progression of $\mathrm{CH}$ has also been associated with the induction of oxidative stress, mitochondrial membrane depolarization, and apoptosis [12].

Recently, there has been a growing interest in the treatment of diseases with traditional Ayurvedic medicines [14-17]. Yogendra Ras (YDR) is an ancient, traditional Indian metal-based formulation that has been prepared using Ras Sindoor (herbally processed sulfur and mercury ash), 28\%; Loha bhasma (herbally processed iron ash); Swarna bhasma (herbally processed gold ash); Abhrak bhasma (herbally processed mica ash); Shuddha Mukta (a powdered form of pearl ash); Vang bhasma (herbally processed tin ash), 14\% each; along with Aloe vera leaves juice as the binding agent. This Ayurvedic formulation is prepared as per the procedures described in the several century-old ancient Indian medicinal texts of Bhaișajya Ratnāvali and Vatavyadhi Chikitsa, for healing neuropathological, cardiovascular and diabetes diseases [18,19]. In Bhaișajya Ratnāvalī (Vātavyādhyādhikāra; 506-512), the sloka (in sanskrit) mentions "Viśuddham rasasindūram taddwardham śuddhahāțakam. Tatsamam kāntalauhñca tatsamañcābhrameva ca. Viśuddham mauktikañcaiva vaṅgañca tatsamam matam. Kumarikārasairbhāvayam dhānyarāśau dinatrayam" (Translation: Herbally processed mercury (Rasasindūra), gold (Hātaka) ash (Bhasma), iron (Kāntalauha) ash, mica (Abhra) ash, pearl (Mauktika) ash, tin (Vanga) ash are to be mixed in Aloe vera juice (Kumārī rasa) and triturated (bhaāvanā) in a vessel (kharala). It is then mixed under pressure (Mardāna) in Kumārī rasa; made into pellets and dried. The pellets are to be wrapped with Ricinus communis (Eranḍa) leaves and kept in a heap of dry Oryza sativa (Dhānya) seeds for 3 days, before use). The prescribed human dosage of the YDR according to Bhaishajya Ratnavali is $125 \mathrm{mg}$ twice a day [18]. Though there are some concerns regarding the safety effects of pure $\mathrm{Hg}$, in the ancient Indian and Chinese medicinal systems, $\mathrm{Hg}$ containing herbally processed medicines have been prescribed for healing skin, heart, and neurological diseases $[20,21]$.

In the current study, we set up a $D$. rerio $\mathrm{CH}$ model, measured cardiac electrical activities, and tested the efficacy of YDR in protecting against drug (ERY)-induced CH. Parameters measured were modulation of electrocardiogram PQRST waves, change in heart size, production of C-reactive protein (CRP), and platelet aggregation. The mode of action for the YDR was studied under in-vitro conditions in the ISP-stimulated murine cardiomyocytes (H9C2) by measuring parameters such as the intonation of oxidative stress, mitochondrial dysfunction, and clinical and non-clinical cell signaling biomarkers for cardiac function. 


\section{Materials and Methods}

\subsection{Source of Test Compounds and Reagents}

Yogendra Ras (YDR) (batch number A-YGR011) was procured from Divya Pharmacy, Haridwar, India, sold under its classical name. Based on sensory characterizations, the YDR formulation was observed to be a dry, free-flowing powder and rust-brown in color, packed under inert environment. The YDR powder in dried condition was odorless, tasteless, and insoluble in water and cell culture media due to its metal-based origin under normal physiological $\mathrm{pH}$ and temperature. Reagents for cell culture studies such as Dulbecco's modified Eagle medium (DMEM), fetal bovine serum (FBS), antibiotics, trypsin-EDTA, isoproterenol, $2^{\prime}, 7^{\prime}$-dichlorofluorescein diacetate (DCFDA), MitoTracker red dye, TaqMan primers and universal RT-PCR master mix for quantitative real-time PCR analysis were purchased from Thermo Fisher Scientific Inc., USA. Purified catalase enzyme was purchased from Merck India Pvt Ltd. Purified superoxide dismutase standards were purchased from Cayman Chemicals, USA. Trichloroacetic acid and Giemsa stain were purchased from Hi-media Laboratories, India. Verapamil was purchased from Sigma-Aldrich, India, and erythromycin was purchased from TCI Chemicals, India.

\subsection{Physicochemical Analysis of the Yogendra Ras (YDR)}

The morphological and elemental attributes of the dry YDR powder were measured using a scanning electron microscope (SEM; LEO-438 VP) with an attached electron dispersive X-ray analysis system (Carl Zeiss, Germany). Gold sputtering of the YDR sample to improve the electron micrograph quality was done at an accelerated voltage of $10 \mathrm{kV}$. Powder X-ray diffraction (XRD) analysis was performed using a Rigaku D-Max 2200 X-ray diffractometer applying Cu-K $\alpha$ radiation at $40 \mathrm{kV} / 40 \mathrm{~mA}$. Scanning was performed throughout the experiment at a step width of $0.02^{\circ}$ over an angular range of $5^{\circ}$ to $80^{\circ}$ and a scanning rate of $0.5^{\circ} \mathrm{min}^{-1}$.

For particle size distribution analysis, the YDR sample was suspended individually at a concentration of $100 \mathrm{mg} / \mathrm{mL}$ in double-distilled water and in the DMEM cell culture media containing $2 \%$ FBS. Measurements were done in triplicates using the Malvern Zetasizer Nano ZS (Malvern Panalytical, United Kingdom). Inductively coupled mass spectroscopy (ICP-MS) analysis of the YDR samples was performed at the Eurofins Analytical Services India Private Limited, Bengaluru, India.

\subsection{Experimental Animals: D. rerio Maintenance}

D. rerio obtained from the in-house breeding facility at Pentagrit Research, Chennai, India were used in the current study. A total of 216 adult male $D$. rerio with a bodyweight of $0.5 \mathrm{~g}$ and length of 25-30 mm were selected for this study. The fish were divided randomly into two groups and acclimatized as 12 fish per polycarbonate tank containing $2 \mathrm{~L}$ of water, prior to the effective and therapeutic dose studies. Throughout the study duration, a period of light $(14 \mathrm{~h})$ and dark (10 h) cycle and a constant water temperature of $27 \pm 1^{\circ} \mathrm{C}$ were maintained. The fish were fed TetraMin ${ }^{\circledR}$ flakes obtained from Tetra, VA. Fish were divided into 9 groups containing 24 fish per group. All the experiments were performed following the protocol approved by the Institutional Animal Ethics Committee (IAEC) in accordance with the Committee for the Purpose of Control and Supervision of Experiments (CPCSEA), Government of India (approval number: 222/Go102019/IAEC), and were in general compliance with the ARRIVE guidelines [22].

\subsubsection{Step 1: Cardiac Hypertrophy Induction in D. rerio}

Inducer stock of erythromycin was prepared by dissolving it at the concentration of $2 \mathrm{mg} / \mathrm{mL}$ in $0.9 \%$ saline solution and was stored at $-20{ }^{\circ} \mathrm{C}$ until further use. For the induction of $\mathrm{CH}, 50 \mu \mathrm{L}$ of the stock solution (100 $\mu \mathrm{g}$ of erythromycin) was added to $4 \mathrm{~L}$ of the housing water of D. rerio. All the erythromycin-exposed fish were maintained for a period of 16 days in case of an effective dose study and for 23 days in case of a therapeutic dose study (Figure 1). In the normal control fish, 
an equivalent volume of $0.9 \%$ saline solution was added to the housing water. Normal control and erythromycin-exposed fish were observed and stabilized from day 5 onwards for the initiation of YDR/verapamil treatments.

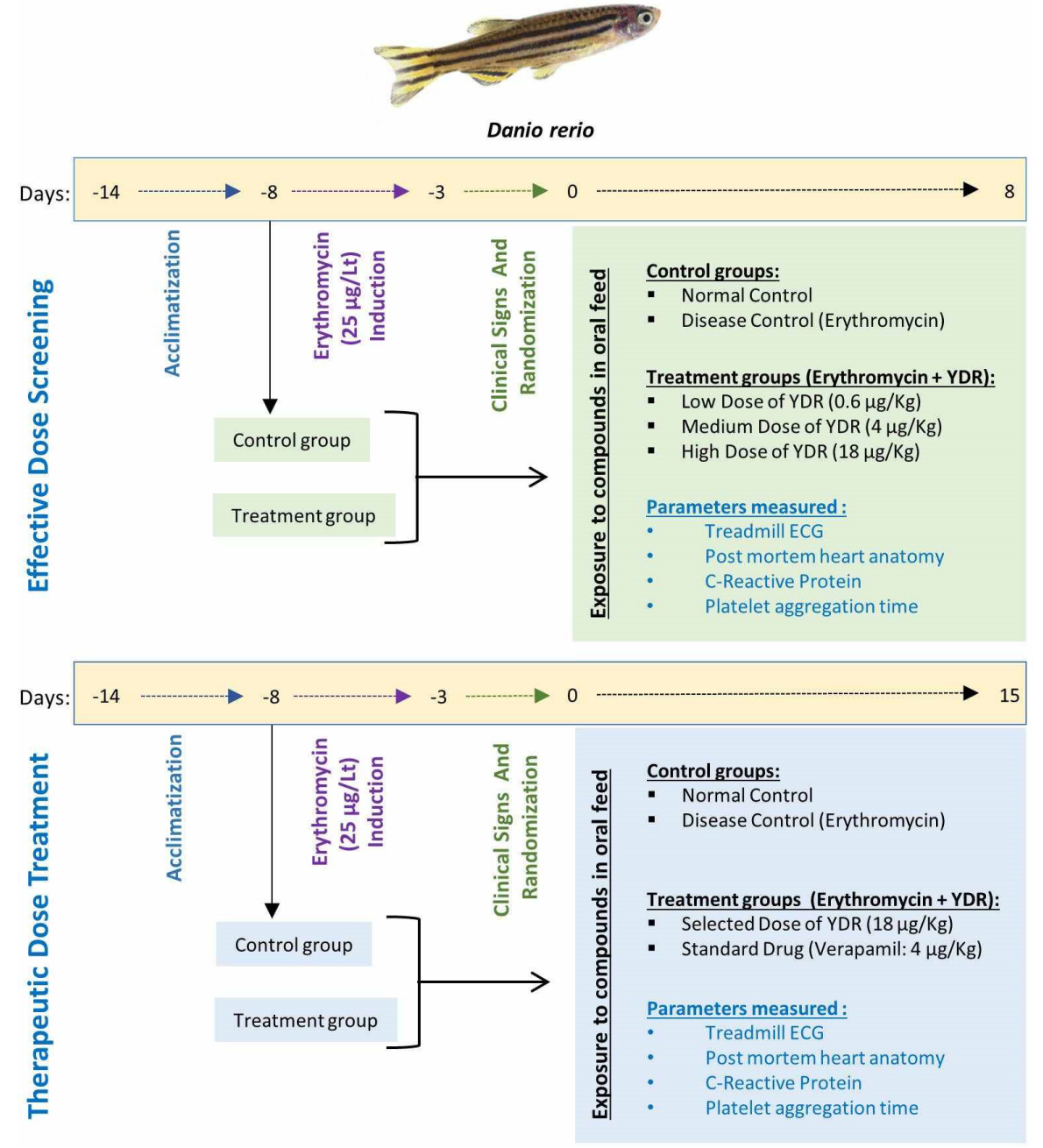

Figure 1. Experimental design of D. rerio exposure to cardiac hypertrophy induction by erythromycin. Duration of the effective dose study was 7 days, and for therapeutic dose study it was 14 days.

\subsubsection{Step 2: Dosing of Test Articles in D. rerio}

YDR doses for D. rerio were optimized at $1000 \times$ less than the relative human doses (125 mg/day BID) by body weights $[23,24]$. Hence, the doses selected for the "effective dose screening" in D. rerio were $0.6,4$, and $18 \mu \mathrm{g} / \mathrm{kg}$ (Figure 1). Standard-of-care cardiac drug, verapamil was given to the fish at the concentration of $4 \mu \mathrm{g} / \mathrm{kg}$ (human equivalent dose). For oral exposure, the selected amount of YDR formulation was mixed with the known mass of the fish feed (TetraMin ${ }^{\circledR}$ ) and was extruded into uniform pellets. For feeding individual fish, a rectangular fish tank was separated into 6 independent units, and individual fish were separated from the respective study groups. Each fish was fed individually on a $24 \mathrm{~h}$ cycle with an estimated number of pellets, under isolated condition. Control fish were fed with unmodified fish feed under conditions similar to the exposed groups.

\subsection{Treadmill Electrocardiography Analysis}

Unlike the human heart, $D$. rerio heart is comprised of a single ventricle and a single atrium. The cardiac functions are cyclic with every systole where the ventricle pumps blood into the bulbus arteriosus; this acts as a reservoir from which blood empties into the ventral aorta [25]. In D. rerio, 
the heart is anatomically located right in the midline of the ventral side, immediately below the gills. The bulbus arteriosus is present on the dorso-cranial side of the ventricle. The ventricle apex is directed to the trunk. To measure the treadmill ECG, the study fish were transferred to experimental treadmill tanks as described by Depasquale et al. [26]. The treadmill tank is a glass tank consisting of 6 chambers of uniform size to study 6 samples at a time. Each chamber has a water inlet and outlet drain pipe. The water flow rate was maintained at $230 \mathrm{~L} / \mathrm{h}$. Fish were aerobically challenged to swim in the controlled water flow rate and water velocity. A maximum velocity of $0.5 \mathrm{~m} / \mathrm{sec}$ was used in the treadmill chambers for fish. Fish were first introduced to a pre-treatment chamber, which is similar to the treadmill chamber. The water flow rate and water velocities were $23 \mathrm{~L} / \mathrm{h}$ and $0.05 \mathrm{~m} / \mathrm{sec}$, respectively, in the pre-treatment chamber; this prevents sudden anxiety and bias in measurements. The fish were allowed to acclimatize for $5 \mathrm{~min}$ in the pre-treatment chamber and were shifted to the treadmill chamber. Fish were exposed in the treadmill chamber for 3 min each, after which the ECG was assessed.

Three-channel ECGs were used to measure the electrocardiograph cardiac signatures [27]. The channels were distributed as two on the head and one to the caudal region. In the head, channels were placed on either side of the gills closer to the heart. The caudal channel was placed on the region where the trunk connects to the caudal region. The ECG was recorded at $20 \mathrm{mV}$ and at a speed of $5 \mathrm{~mm} / \mathrm{sec}$. Observations were recorded, and ECG graphs were analyzed statistically. Induction of $\mathrm{CH}$ was calculated on the basis of Cornell product, Cornell voltage, Sokolow-Lyon, and Romhilt-Estes point criteria [28].

\subsection{Measurement of Platelet Aggregation and C-Reactive Protein (CRP)}

Fish were sedated in cold water set at $14{ }^{\circ} \mathrm{C}$. A small slit was made injuring the major blood vessel in the tip caudal region of the fish using a sharp scalpel. Care was taken to keep the fish alive until the clotting time was recorded. The cut was approximately $0.25 \mathrm{~mm}$ deep passing through the scales and the skeletal muscle. Blood was collected and immediately spotted on a glass slide. Whole blood was observed under a light microscope at $4 \times$, and the platelet aggregation was measured as a parameter for the blood clotting time.

After measurement of the platelet aggregation, all the study fish were euthanized immediately using ice-cold water set at $4{ }^{\circ} \mathrm{C}$. Blood was collected in a glass tube containing $5 \mu \mathrm{L}$ of $0.5 \%$ EDTA by making an incision in the region of the dorsal aorta and inferior vena cava, just posterior to the dorsal fin near the caudal region. EDTA-treated whole blood was then centrifuged at 10,000 RPM for 10 min to separate the plasma. Collected plasma was then stored at $-80{ }^{\circ} \mathrm{C}$ until further use, and CRP levels were measured using the Randox CRP analysis kit and auto-analyzer system (Randox Laboratories Ltd., United Kingdom).

\subsection{Post-Mortem Heart Anatomy}

Heart was dissected out from the euthanized fish. The isolated heart was immersed and stored in $30 \%$ formalin solution for $72 \mathrm{~h}$. Post-fixative treatment of the heart was dissected in the cross-sectional direction into 3 parts. The middle section was used to measure the septal wall thickness. Microscopic images of the heart were taken at $4 \times$ magnification and the thickness was measured using Image J software.

\subsection{In-Vitro Cell Culture}

The H9C2 (rat embryonic cardiac) cells were purchased from the ATCC licensed cell repository National Centre for Cell Science (NCCS), Pune, India. The H9C2 cells were cultured in DMEM media supplemented with $10 \%$ fetal bovine serum (FBS) and $1 \%$ antibiotics. Cells were cultured at the density of $2 \times 10^{6}$ cells $/ \mathrm{cm}^{2}$ and grown in a humidified incubator at $37^{\circ} \mathrm{C}$ with $5 \% \mathrm{CO}_{2}$. For the experiments, cells were plated in 96-well plates at the density of 10,000 cells/well. The cells were pre-incubated before exposure to the stimulant and the drugs. 


\subsection{Cell Viability Assay}

H9C2 cells were treated with ISP or YDR mixed in fresh cell culture media in semi-log doses between 0 and $1000 \mu \mathrm{g} / \mathrm{mL}$ for $24 \mathrm{~h}$. At the end of the exposure time, the old medium was removed, and cells were washed with $100 \mu \mathrm{L}$ PBS. A total of $100 \mu \mathrm{L}$ of $0.5 \mathrm{mg} / \mathrm{mL}$ 3-(4,5-dimethylthiazol-2-yl)-2,5-diphenyltetrazolium bromide (MTT) was added to each well, and the plates were incubated for $3 \mathrm{~h}$ at $37^{\circ} \mathrm{C}$. At the end of the exposure period, $75 \mu \mathrm{L}$ of MTT dye was removed. Fifty microliters of DMSO was added, and the plates were placed on a shaker for $10 \mathrm{~min}$. The absorbance of each well was read using the PerkinElmer Envision microplate reader at $595 \mathrm{~nm}$ wavelength, and cell viability percentage was calculated along with an inhibitory concentration of $20 \%$ $\left(\mathrm{IC}_{20}\right)$ and $50 \%\left(\mathrm{IC}_{50}\right)$.

\subsection{Determination of Intracellular Oxidative Stress}

H9C2 cells were exposed to ISP $(50 \mu \mathrm{M})$ and YDR $(30 \mu \mathrm{g} / \mathrm{mL})$ individually or in combination for $24 \mathrm{~h}$. At the end of the exposure period, cells were washed with lukewarm PBS, and fresh media containing $10 \mu \mathrm{g} / \mathrm{mL}$ of $2^{\prime}, 7^{\prime}$-dichlorofluorescein diacetate (DCFH-DA) dye was added to all the wells. The plates were incubated in the dark for $45 \mathrm{~min}$ at $37^{\circ} \mathrm{C}$. Fluorescence intensity was measured using the PerkinElmer Envision microplate reader at the excitation and emission wavelengths of 490 and $520 \mathrm{~nm}$, respectively.

\subsection{Mitochondrial Membrane Potential Assay}

H9C2 cells were exposed to ISP $(50 \mu \mathrm{M})$ and YDR $(30 \mu \mathrm{g} / \mathrm{mL})$ individually or in combination for $24 \mathrm{~h}$. At the end of the exposure period, the cells were washed with lukewarm PBS and stained with 1 $\mathrm{mM}$ of MitoTracker Red probes for $45 \mathrm{~min}$. Cells were washed with $1 \times$ HBSS buffer after removing staining media, and fluorescence intensity was measured on the PerkinElmer Envision microplate reader with excitation and emission at 584 and $606 \mathrm{~nm}$, respectively.

\subsection{Nitroblue Tetrazolium Assay for Superoxide Generation}

H9C2 cardiomyocytes were seeded in the 6-well culture plate, and after $60-70 \%$ confluence, cells were treated with ISP and YDR each for $24 \mathrm{~h}$. After the completion of the exposure, $0.3 \%$ NBT was added to each well and incubated for $1 \mathrm{~h}$ in an incubator at $37^{\circ} \mathrm{C}$ with $5 \% \mathrm{CO}_{2}$. Cells were counterstained with $2 \%$ safranin for $10 \mathrm{~min}$. Stained cells were observed under an inverted microscope at $10 \times$ for the formation of blue-purple formazan crystals. The formazan crystals were solubilized with $2 \mathrm{M} \mathrm{KOH}$ and $0.5 \mathrm{~N} \mathrm{HCl}$ to calculate the percentage of NBT reduction [29]. Elution was taken out in a 96-well plate, and absorbance was measured at $630 \mathrm{~nm}$ in a plate reader. The stimulation index was calculated by the ratio of absorbance of treated and control cells.

\subsection{Isolation and Quantification of Total Cell Proteins}

H9C2 cells were exposed to ISP $(50 \mu \mathrm{M})$ and YDR $(30 \mu \mathrm{g} / \mathrm{mL})$ individually or in combination for $24 \mathrm{~h}$. At the end of the exposure period, the cells were washed with lukewarm PBS, trypsinized, and lysed in RIPA buffer $\mathrm{NaCl}(150 \mathrm{mM}), \mathrm{NP}-40$ (10\% v/v), Tris-HCl (50 mM; pH 7.5), EDTA (1 mM), PMSF, and protease inhibitor cocktail and incubated for $1 \mathrm{~h}$ on ice with intermittent tapping. The lysate was then centrifuged at $13,000 \mathrm{rpm}$ for $10 \mathrm{~min}$ at $4{ }^{\circ} \mathrm{C}$. Protein concentration was quantified in the collected supernatant using a BCA kit (Thermo Fisher Scientific Inc., USA) as per the manufacturer instructions. Unused supernatant was stored at $-80^{\circ} \mathrm{C}$ for further analysis.

\subsection{Catalase Enzyme Assay}

Catalase activity was measured in isolated proteins as per the method mentioned by Weydert et al. [30]. Initially, absorbance was adjusted between 1.150 and 1.200 by diluting $300 \mu \mathrm{L}$ of $\mathrm{H}_{2} \mathrm{O}_{2}(30 \% v / v)$ in $100 \mathrm{~mL}$ of potassium phosphate buffer. Then, $125 \mu \mathrm{g} / \mathrm{mL}$ of extracted protein was 
added to $0.1 \mathrm{M}$ potassium phosphate buffer ( $\mathrm{pH} 7.0$ ), and the reaction was initiated by adding $30 \mathrm{mM}$ $\mathrm{H}_{2} \mathrm{O}_{2}$. Absorbance was recorded spectrophotometrically for every $30 \mathrm{~s}$ at a wavelength of $240 \mathrm{~nm}$ for $3 \mathrm{~min}$ in a quartz cuvette. Purified catalase was used to plot the standard curve. The enzyme activity was expressed as millimolar $\mathrm{H}_{2} \mathrm{O}_{2}$ consumed per min per mg of protein.

\subsection{Superoxide Dismutase (SOD) Enzyme Assay}

SOD enzyme activity was measured based on the method of Beauchamp and Fridovich using Cayman's superoxide dismutase assay kit as per the manufacturer instructions [31]. The reaction was processed by adding $200 \mu \mathrm{L}$ of the diluted radical detector ( $1.5 \mathrm{mM}$ nitroblue tetrazolium chloride) in $20 \mu \mathrm{L}$ of isolated protein, and the reaction was initiated under direct white light at interval 0 by adding $10 \mu \mathrm{L}$ of diluted $0.12 \mathrm{mM}$ riboflavin in a 96-well plate. The plate was incubated in light on a shaker for $12 \mathrm{~min}$, and absorbance was recorded at $560 \mathrm{~nm}$ using a plate reader. Purified SOD was used to plot the standard curve, and the amount of enzyme required to inhibit the reduction of NBT by $50 \%$ and the activity was expressed as units/mL of protein.

\subsection{Determination of mRNA Expression Level of Clinical and Non-Clinical Cardiac Biomarkers}

Gene expression studies using quantitative real-time PCR (qRT-PCR) were performed to evaluate the mRNA expression level of clinical and non-clinical cardiac biomarkers in H9C2 cells. The cells were exposed to ISP $(50 \mu \mathrm{M})$ and YDR $(30 \mu \mathrm{g} / \mathrm{mL})$ individually or in combination for $24 \mathrm{~h}$. At the end of the exposure period, the cells were washed with lukewarm PBS and lysed using TRIZOL reagent (Thermo Fisher Scientific Inc., USA), and total RNA was isolated. RNA was purified and quantified by taking absorbance at 260 and $280 \mathrm{~nm}$. Each RNA sample was processed to cDNA using a one-step Verso cDNA synthesis kit (Thermo Fisher Scientific Inc., USA). For qRT-PCR, TaqMan chemistry-based FAM single tube primer assays of NOX-2 and -4, COX-2, ANF, CLRS-1, TNN-T and TNN-I, along with TaqMan universal master mix were used. Beta-actin (ACTB) housekeeping gene was used as an internal control to normalize the expression of other genes. Real-time PCR assay was run on a Biometra TProfessional RT-PCR machine (Analytik-Jena AG, Germany), and cycling parameters included initial denaturation at $95^{\circ} \mathrm{C}$ for $10 \mathrm{~min}$ and primer extension at $95^{\circ} \mathrm{C}$ for $15 \mathrm{~s}$ and $60^{\circ} \mathrm{C}$ for one min with 40 cycles. Ct values were obtained, relative expression $2^{-\Delta \Delta C t}$ was calculated, and data were analyzed for fold change in mRNA expression.

\subsection{Statistical Analysis}

All the experiments were performed in technical triplicates as well as in biological triplicates. Data from all the experiments are presented as the mean \pm SEM. An unpaired $t$-test was used for comparison between two groups. For groups of three or more, the data were subjected to one-way analysis of variance (ANOVA) followed by Dunnett's post-hoc test. Differences were considered statistically significant if the $p$-value was $\leq 0.05$.

\section{Results}

\subsection{Physicochemical Properties of Yogendra Ras (YDR) Particles}

Evaluation of the scanning electron microscope (SEM) images of YDR showed them to be heterogeneous in shape and size (Figure 2A). YDR was found in the particulate form either present loosely or in large clusters with diameters of $<100 \mathrm{~nm}$ to $\sim 1 \mu \mathrm{m}$. Surface chemical characterization of the YDR using the electron dispersive $\mathrm{X}$-ray (EDX) technique identified the presence of mercury $(\mathrm{Hg})(37.75 \pm 1.92 \%)$; tin $(\mathrm{Sn})(30.05 \pm 3.35 \%)$; oxygen $(\mathrm{O})(14.90 \pm 1.08 \%)$; calcium $(\mathrm{Ca})(12.86 \pm 1.99 \%)$; iron $(\mathrm{Fe})(5.44 \pm 0.45 \%)$; silicon $(\mathrm{Si})(2.44 \pm 0.26 \%)$; and traces of $(<1 \%)$ magnesium $(\mathrm{Mg})$, sodium $(\mathrm{Na})$, aluminum $(\mathrm{Al})$, and zinc $(\mathrm{Zn})$ on the surface of the YDR particles (Figure $2 \mathrm{~B}, \mathrm{C}$ ). 
A

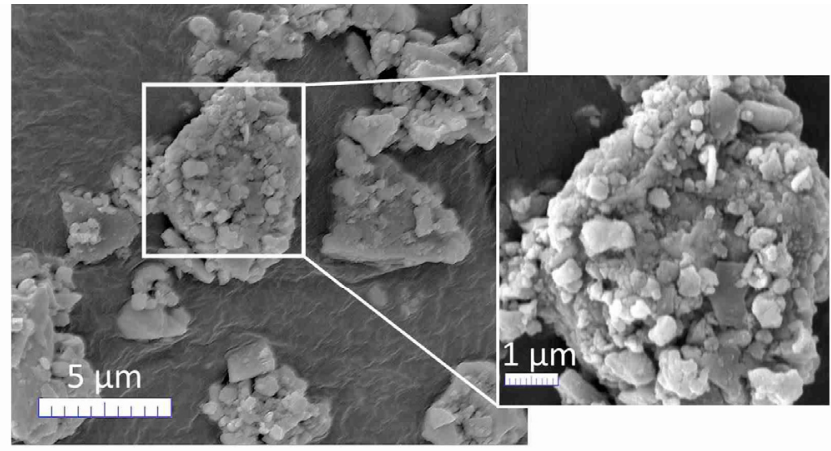

B

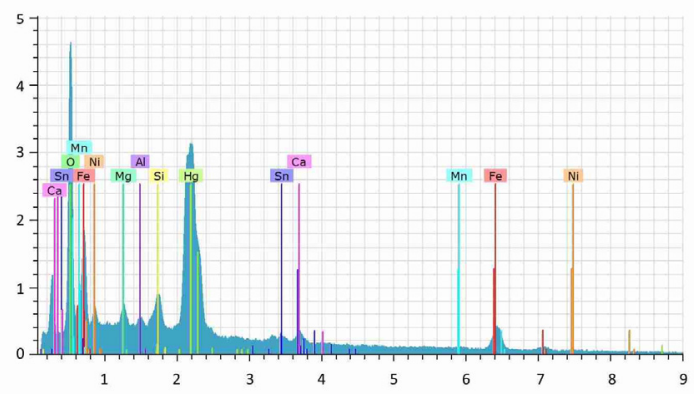

C

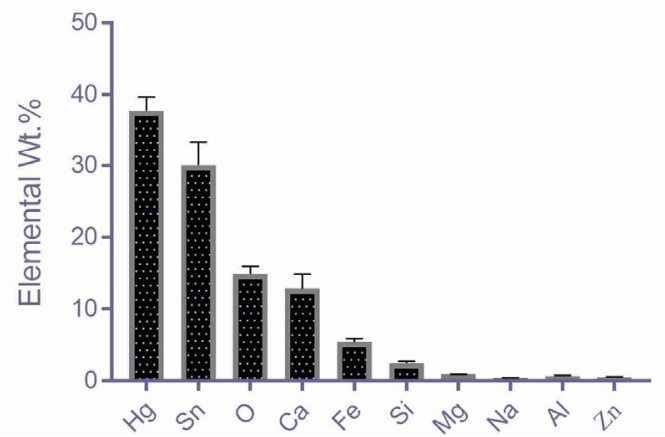

Figure 2. Scanning electron microscope (SEM) and electron dispersive X-ray (EDX) analysis of Yogendra Ras (YDR). (A) SEM analysis of the YDR powder showed the presence of a heterogeneous mass of particles of varying shapes and sizes. Particles were present individually or as aggregates. (B) Electron dispersive X-ray analysis showed the presence of various elements on the surface of the YDR particles. (C) Quantitatively highest elemental concentrations were detected for mercury $(\mathrm{Hg})$, tin (Sn), oxygen $(\mathrm{O})$, calcium $(\mathrm{Ca})$ and iron $(\mathrm{Fe})$. Several other elements such as silicon $(\mathrm{Si})$, magnesium $(\mathrm{Mg})$, sodium $(\mathrm{Na})$, aluminum $(\mathrm{Al})$, and zinc $(\mathrm{Zn})$ were also detected but at $\leq 1 \% w / w$ concentrations.

Inductively coupled plasma mass spectroscopy (ICP-MS) analysis of YDR samples showed the presence of $9.8 \%$ mercury $(\mathrm{Hg})$ and $7.9 \%$ gold $(\mathrm{Au})$. X-ray diffraction (XRD) crystallography analysis of the YDR sample confirmed the presence of $\mathrm{Hg}$ in the form of Cinnabar and Metacinnabar $(\mathrm{HgS})$ (Figure 3A). Using the XRD analysis, the presence of pure gold ( $\mathrm{Au})$, hematite $\left(\mathrm{Fe}_{2} \mathrm{O}_{3}\right)$, arsenic trioxide $\left(\mathrm{As}_{4} \mathrm{O}_{6}\right)$, and AsFe were identified in the YDR samples (Figure 3A). Several other crystal peaks were also detected in low amounts in the XRD analysis. Dynamic light scattering (DLS) analysis of the YDR particles showed a size distribution transformation when the suspension medium was changed from water to complete cell culture media. In pure water suspension, YDR showed a bimodal size distribution with an average dynamic size distribution of $1116.00 \pm 102.70$ d.nm (Figure 3B). However, when suspended in the DMEM media supplemented with $2 \%$ FBS, YDR size distribution changed to a monomodal distribution showing a size of $486.40 \pm 46.95$ d.nm. 
A

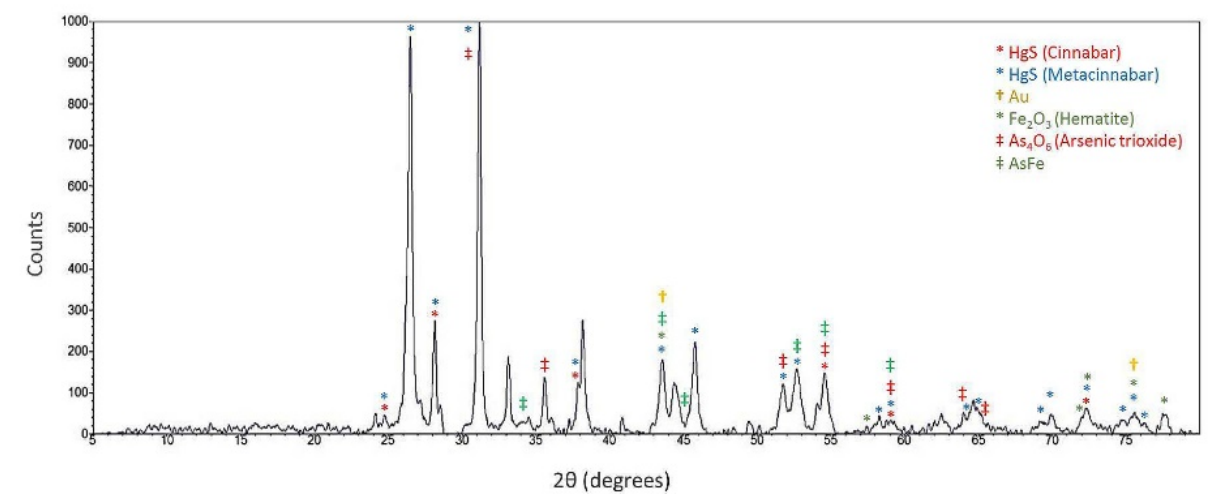

B

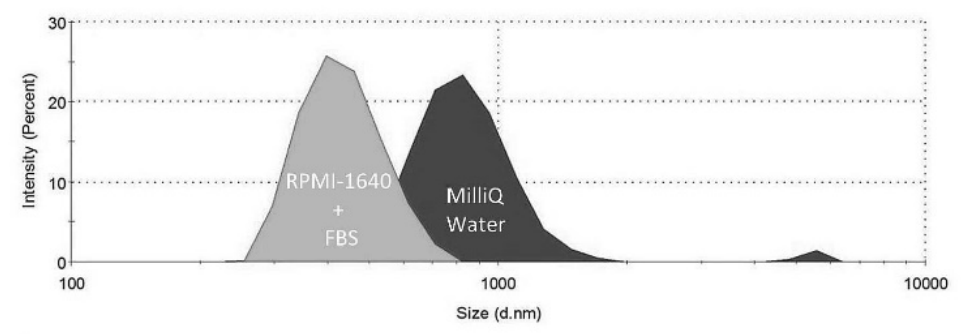

\begin{tabular}{lcc}
\hline $\begin{array}{l}\text { Colloidal Suspension } \\
\text { of YDR }\end{array}$ & $\begin{array}{c}\text { Size Distribution } \\
\text { (d.nm) }\end{array}$ & $\begin{array}{c}\text { Polydispersity Index } \\
\text { (PdI) }\end{array}$ \\
\hline $\begin{array}{l}\text { In MilliQ Water (pH } \\
\text { 6.0) }\end{array}$ & $1116 \pm 102.7$ & $0.406 \pm 0.08$ \\
$\begin{array}{l}\text { In RPMI-1640 media } \\
\text { with 2\%FBS }\end{array}$ & $486.4 \pm 46.95$ & $0.174 \pm 0.059$ \\
\hline
\end{tabular}

Figure 3. X-ray diffraction (XRD) and size distribution analysis of dry Yogendra Ras (YDR) sample. (A) XRD analysis showed the presence of cinnabar $(\mathrm{HgS})$, metacinnabar $(\mathrm{HgS})$, pure gold ( $\mathrm{Au})$, hematite $\left(\mathrm{Fe}_{2} \mathrm{O}_{3}\right)$, arsenic trioxide $\left(\mathrm{As}_{4} \mathrm{O}_{6}\right)$, and arsenic-iron alloy (AsFe). (B) Dynamic light scattering analysis of the YDR showed them to be present in a bimodal phase when suspended in pure MilliQ water. The size distribution showed the presence of particles with a hydrodynamic diameter of $1116 \pm 102.7$ d.nm along with a high polydispersity index (PdI) value representing an unstable colloidal suspension. When the YDR particles were suspended in cell culture media containing $2 \%$ FBS, the particle size distribution changed to a monomodal distribution showing the hydrodynamic diameter of $486 \pm 46.95$ d.nm and a lower PdI value representing a stable colloidal suspension.

Change in the size distribution of the YDR particles in the presence of the cell culture media biomolecules was further supported by the polydispersity index (PdI) values indicating that the YDR particles formed a more stable colloidal suspension in the DMEM cell culture media supplemented with $2 \% \mathrm{FBS}(\mathrm{PdI}=0.174 \pm 0.06)$ as compared to the particles suspended in pure water ( $\mathrm{PdI}=0.406 \pm$ 0.080) (Figure 3B).

Anatomical analysis of the normal control D. rerio heart showed structurally intact bulbus arteriosus, atrium, and ventricle (Figure $4 \mathrm{~A}, \mathrm{Bi}$ ). Heart retained a dense red color of the ventricle in the normal fish (Figure $4 \mathrm{Bi}, \mathrm{Ci}$ ). Heart anatomy analysis of the disease control fish post-7-day exposure to ERY showed intact bulbus, atrium, ventricle regions, and normal coloration (Figure 4Bii). However, after 14 days of exposure to ERY, significant anatomical changes representing hypertrophy 
were observed in the heart of the disease control fish with the appearances of dark coloration as compared to the normal control fish (Figure 4Cii). Septum wall thickness analysis showed a significant ( $p$-value $<0.001$ ) time-dependent septum wall thickness increase in the ERY-stimulated $D$. rerio in comparison to the normal control fish (Figure 5A). Measurement of the ECG parameters in the effective dose study showed the normal control fish to have a regular PQRST deflection with standard intervals and segments. The normal fish showed a heartbeat between 140 and 150 beats per minute confirming the amplitude of 0.5 millivolts $(\mathrm{mV})$ deflection for the QR wave (Figure $4 \mathrm{Bi}, \mathrm{Ci})$. Induction of $D$. rerio with erythromycin (ERY; $25 \mu \mathrm{g} / \mathrm{Lt}$ ) for both the 7-day (effective dose screening) and 14-day (therapeutic dose testing) exposure studies showed a widening in the angle of QRS complex compared to the normal control fish (Figure 4Bi,Bii,Ci,Cii). The $\mathrm{R}$ wave showed an increase of $5 \mathrm{~mm}$, and the $\mathrm{S}$ wave showed a dip by $3 \mathrm{~mm}$ indicating an increase in the Cornell voltage criteria and an increase in wave amplitudes. The resulting increase in the time for completion of a single beat was determined to be 0.2 decaseconds compared to the normal control fish (Figure 4Bi,Bii,Ci,Cii). Additional ECG markers determined for the inception of the $\mathrm{CH}$ in the disease control fish were Sokolow-Lyon criteria, as observed in Cornell voltage criteria and Cornell product criteria, and Romhilt-Estes point through an ST elevation of $0.025 \mathrm{mV}$ for the isoelectric segment of the time period (Figure 4Bii,Cii).

\subsection{YDR Ameliorates Cardiac Hypertrophy and Associated Heart Anatomical Abnormalities}

For the effective dose screening, the ERY-induced $D$. rerio were treated with three doses of YDR: low $(0.6 \mu \mathrm{g} / \mathrm{kg})$, medium $(4 \mu \mathrm{g} / \mathrm{kg})$, and high $(18 \mu \mathrm{g} / \mathrm{kg})$ (Figure 1, Figure 4Biii-v). Anatomically, a low dose of YDR + ERY-treated fish showed mild fluid infiltration and heart size increase (Figure 4Biii). The medium YDR dose + ERY-treated fish showed a bulged heart at the ventricle and atrium side and mild fluid infiltration in the bulbus region (Figure 4Biv). The highest YDR dose + ERY-treated fish showed an intact heart with bulbus, atrium, and ventricle (Figure 4Bv). Septum wall thickness analysis indicated that the YDR treatment at the low doses sustained the ERY stimulated increase in the wall thickness, whereas the medium and high dose treatments of YDR significantly ameliorated the increased septal wall thickness (Figure 5A). All the YDR-treated fish showed partial recovery from the ERY-stimulated $\mathrm{CH}$ following the 7-day treatment with an $\mathrm{R}$ wave showing a $2.5 \mathrm{~mm}$ decrease and $\mathrm{S}$ wave dip by $1.5 \mathrm{~mm}$ indicating a decrease in Cornell voltage criteria, as compared to the disease control fish. The decrease in the $\mathrm{R}$ and $\mathrm{S}$ waves showed a reduction in the intensity of $\mathrm{CH}$ stimulated by ERY. However, the presence of amplitude of 0.12 millivolts $(\mathrm{mV})$ indicated the tendency to depolarize the ventricle and induction of mild CH (Figure 4Biii-v). The presence of $\mathrm{CH}$ in the YDR-treated fish was also confirmed as per the Cornell product criteria represented by the presence of QRS angle widening and the additional requirement of 0.2 decaseconds to complete a single beat (Figure 4Biii-v). Additional hypertrophy markers such as the Sokolow-Lyon criteria as observed in Cornell voltage criteria and Cornell product criteria and Romhilt-Estes point also confirmed the presence of $\mathrm{CH}$ in the 7-day YDR + ERY-treated fish, with an ST elevation of $0.0125 \mathrm{mV}$ for the isoelectric segment of the time period (Figure 4Biii-v).

Anatomical analysis of ERY-induced and YDR-treated fish hearts revealed the presence of very mild hypertrophic morphology and normal morphology in the standard-of-care drug verapamil + ERY-treated fish (Figure 4Ciii,iv). Septum wall thickness analysis revealed significant recovery in the ERY-stimulated increase in the wall thickness, by treatment with the therapeutic dose of YDR or standard drug verapamil (Figure 5D). ECG analysis of the therapeutic YDR dose and standard of care drug verapamil-treated $D$. rerio showed a complete recovery of the ERY-stimulated ECG parameters related to the onset of $\mathrm{CH}$, as compared to the disease control fish (Figure 4Cii-iv). All the ECG parameters such as Cornell voltage criteria, Cornell product criteria with QRS angle, Sokolow-Lyon criteria (as per Cornell voltage criteria and Cornell product criteria), and Romhilt-Estes point confirmation with no ST elevation measured in ERY + YDR and ERY + verapamil-treated fish showed parameters equal to those observed in the normal control fish (Figure 4Ci-iv). 
A

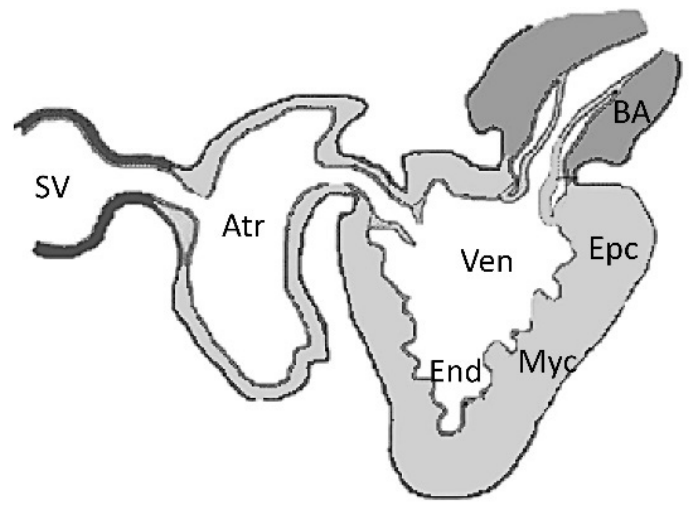

B

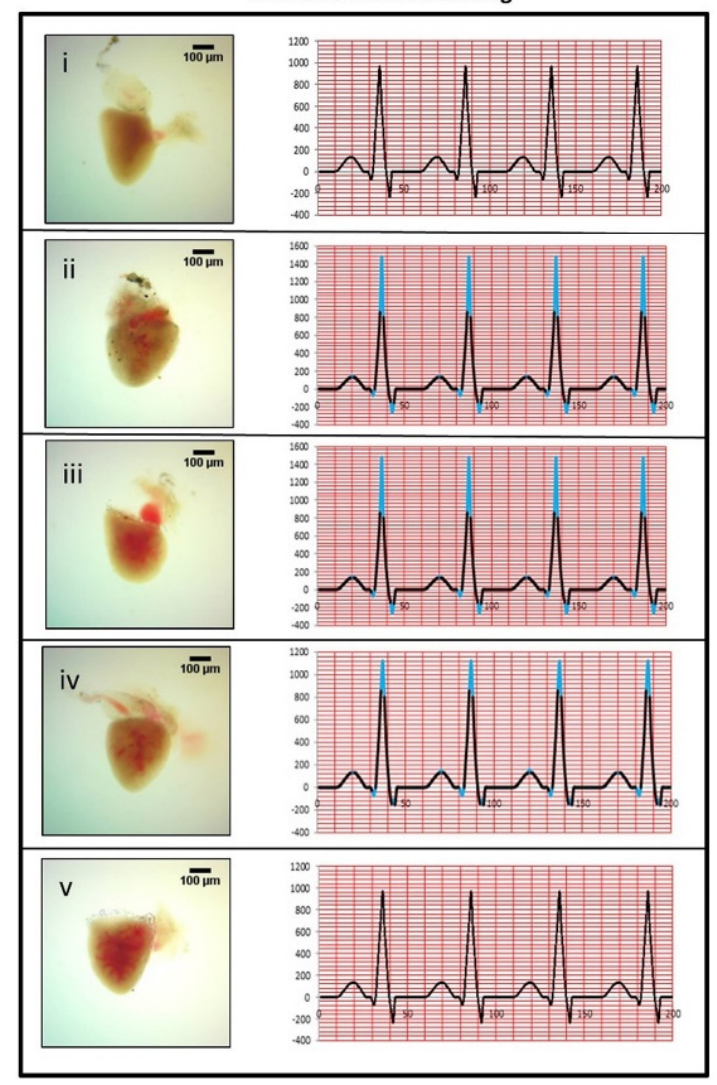

C

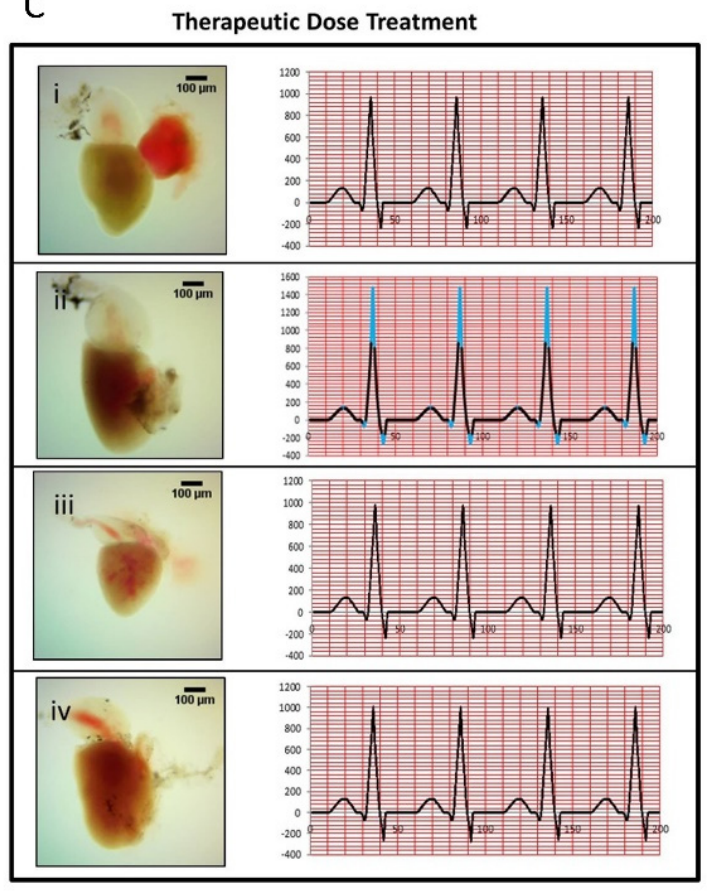

Figure 4. Electrocardiogram (ECG) analysis and whole heart histological analysis of erythromycin (ERY)-stimulated cardiac hypertrophy. (A) Schematic diagram of Danio rerio heart: sinus venosus = $\mathrm{SV}$, atrium $=$ Atr, ventricle $=$ Ven, bulbus arteriosus $=\mathrm{BA}$, epicardium $=\mathrm{Epc}$, myocardium $=\mathrm{Myc}$, endocardium = End (graphics adapted from Yacoub et al. [32]). (B) In the effective dose screening analysis, ECG and heart anatomy of the D. rerio were studied for (i) normal control; (ii) disease control (25 $\mu \mathrm{g} / \mathrm{Lt}$ erythromycin (ERY)); (iii) low dose ( $0.6 \mu \mathrm{g} / \mathrm{kg}$ of YDR); (iv) medium dose (4 $\mu \mathrm{g} / \mathrm{kg}$ of YDR); and $(\mathbf{v})$ high dose $(18 \mu \mathrm{g} / \mathrm{kg}$ of YDR). The results indicated induction of $\mathrm{CH}$ by ERY. No changes were detected in the $\mathrm{CH}$ parameters following the 7 days of effective dose treatment with YDR at the low and medium doses. Mild changes were observed at the highest tested dose of YDR. (C) In the therapeutic

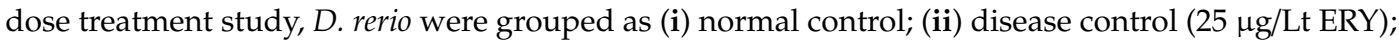
(iii) standard drug ( $4 \mu \mathrm{g} / \mathrm{kg}$ of verapamil); (iv) therapeutic dose of YDR (18 $\mu \mathrm{g} / \mathrm{kg}$ of YDRY). The results indicated that, following 14 days of treatment, both the verapamil and YDR successfully ameliorated the $\mathrm{CH}$ induced by ERY in $D$. rerio. 

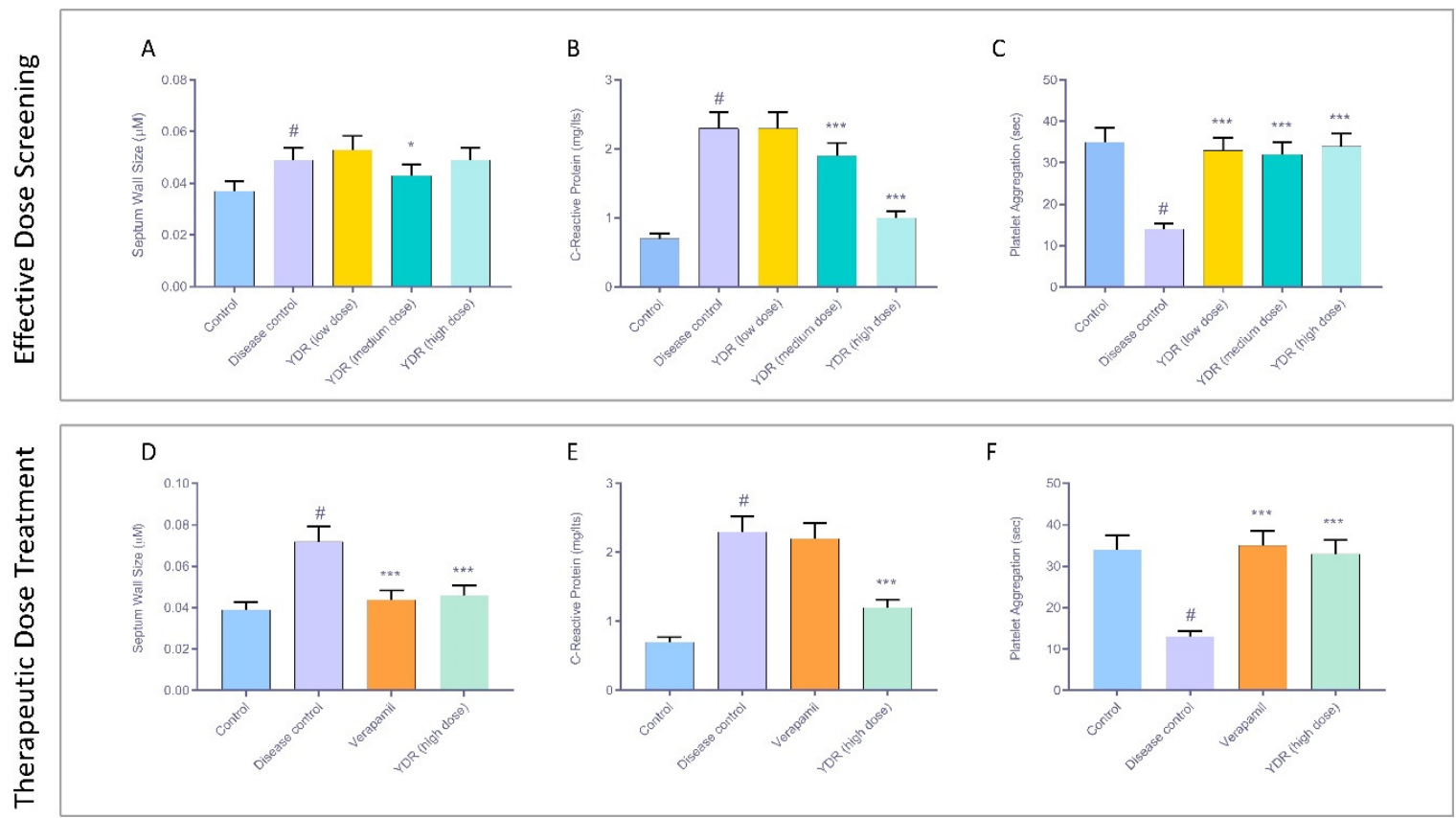

Figure 5. Biomarker analysis for effective dose screening and therapeutic dose treatment of Yogendra Ras (YDR) in Danio rerio stimulated with erythromycin. (A) Effective dose screening of YDR in Danio rerio showed no change in the septum wall thickness of the ERY-stimulated $D$. rerio compared to the disease control. (B) ERY stimulation of the D. rerio significantly increased the systemic release of the inflammatory C-reactive protein. This was reduced in a dose-dependent manner through the treatment of the ERY-stimulated fish. (C) ERY stimulation of the D. rerio significantly decreased the platelet aggregation time. YDR treatment of the ERY-stimulated $D$. rerio at varying concentrations recovered the platelet aggregation time back to normal. (D) Therapeutic treatment of the ERY-stimulated D. rerio with YDR $(18 \mu \mathrm{g} / \mathrm{kg})$ and standard of care drug, verapamil $(4 \mu \mathrm{g} / \mathrm{kg})$ significantly reduced the $\mathrm{CH}$-associated increase in septum wall thickness. (E) Therapeutic treatment of the ERY-stimulated D. rerio with YDR $(18 \mu \mathrm{g} / \mathrm{kg})$ significantly reduced the release of the inflammatory C-reactive protein. Verapamil did not induce any quantitative change in the release of the inflammatory protein. $(\mathbf{F})$ Therapeutic treatment of the ERY-stimulated D. rerio with YDR $(18 \mu \mathrm{g} / \mathrm{kg})$ significantly recovered the stimulated platelet aggregation time back to the normal level. $n=24$. One-way ANOVA followed by Dunnett's post-hoc test was applied to study statistical significance: normal control versus disease control (\# $p$-value $<0.001)$ and YDR/verapamil treatment versus disease control $\left({ }^{*} p\right.$-value $<0.05$; ${ }^{* * *} p$-value $\left.<0.001\right)$.

No mortality was detected in any of the control or treatment groups in the 7-day effective dose screening study. In the therapeutic dose screening study, a total of four mortalities were observed in the disease control fish, probably due to disease severity. No mortality was detected in the YDR therapeutic dose or standard drug treatment groups.

\subsection{YDR Inhibits Stimulated Expression of Serum C-Reactive Protein}

Determination of the C-reactive protein (CRP) levels present in the blood serum of the D. rerio in the effective dose screening showed a significant increase in protein expression on ERY stimulation (Figure 5B). Elevated levels of CRP have been associated with increased cardiovascular risks like left ventricle hypertrophy and hypertension in children and adults [33]. Hence, in our study, elevated levels of CRP represented the development of $\mathrm{CH}$ in the fish following induction with ERY. Treatment of the fish with varying concentrations of the YDR formulation led to a concentration-dependent decrease in the elevated levels of CRP (Figure 5C). This reduction represents the modulation of $\mathrm{CH}$ by the YDR as determined using other screening parameters. In the therapeutic study, selecting the highest effective dose $(18 \mu \mathrm{g} / \mathrm{kg})$ of the YDR, a complete normalization in the elevated levels of CRP 
was detected. Interestingly, verapamil $(4 \mu \mathrm{g} / \mathrm{kg})$ did not reduce ERY-stimulated CRP levels. Hence, the results indicated that while verapamil was not able to reverse the acute-phase induction of $\mathrm{CH}$ in the ERY-treated D. rerio, YDR was able to completely ameliorate the drug-induced cardiac effect and underlying mechanism of action (Figure 5E).

\subsection{YDR Effect on Stimulated D. rerio Platelet Aggregation Time}

Clinical studies have shown that patients with cardiac diseases, especially ischemia and cardiomyocyte hypertrophy, tend to show high spontaneous and induced rates of platelet aggregation [34]. In the present study, ERY stimulation of the D. rerio led to a decrease in the platelet aggregation time as compared to the normal control fish (Figure 5C). This ERY stimulated reduction in the platelet aggregation time as a precursor to the development of thrombosis. Treatment of the ERY-stimulated D. rerio with different doses of YDR $(0.6-18 \mu \mathrm{g} / \mathrm{kg})$ significantly $(p$-value $<0.001)$ recovered the platelet aggregation time back to normal as compared to the disease control fish. Therapeutic treatment of the ERY-stimulated fish with YDR $(18 \mu \mathrm{g} / \mathrm{kg})$ and the standard drug verapamil also showed a significant recovery of the platelet aggregation compared to the disease control (Figure 5F).

\subsection{In-Vitro Dose Screening of Yogendra Ras (YDR) and Isoproterenol (ISP) in H9C2 Cells}

Cell viability analysis showed a dose-dependent change in the H9C2 cells following exposure to ISP or YDR (Figure 6A). Based on these results, the inhibitory concentrations of $20 \%\left(\mathrm{IC}_{20}\right)$ and $50 \%$ $\left(\mathrm{IC}_{50}\right)$ for ISP were determined to be 50 and $122.4 \mu \mathrm{M}$, respectively. Similarly, $\mathrm{IC}_{20}$ and $\mathrm{IC}_{50}$ doses for the YDR were determined to be at the concentrations of 30 and $205 \mu \mathrm{g} / \mathrm{mL}$, respectively. On the basis of this dose screening, $50 \mu \mathrm{M}$ of ISP and $30 \mu \mathrm{g} / \mathrm{mL}$ of YDR were selected for the subsequent cell biological experiments.

\subsection{Oxidative Stress Analysis}

The stimulation of H9C2 cells with ISP $(50 \mu \mathrm{M})$ for 24 h produced a significant (p-value $<0.01$ ) 1.3-fold increase in the intracellular ROS generation (Figure 6B). Elevated levels of oxidative stress due to excessive accumulation of reactive oxygen species (ROS) have been reported to induce $\mathrm{CH}$ [12]. Hence, an increase in ROS indicated the stimulated generation of oxidative stress and $\mathrm{CH}$ within the ISP-stimulated H9C2 cells. Concurrent treatment of the ISP (50 $\mu \mathrm{M})$-induced H9C2 cells with varying doses of YDR significantly $(1 \mu \mathrm{g} / \mathrm{mL} p<0.05 ; 3 \mu \mathrm{g} / \mathrm{mL} p<0.05 ; 10 \mu \mathrm{g} / \mathrm{mL} p<0.01 ; 30 \mu \mathrm{g} / \mathrm{mL} p<0.01)$ reduced the intracellular generation of ROS in a dose-dependent manner (Figure $6 \mathrm{~B}$ ).

Mitochondria play an important role in the production and release of intracellular ROS. Stimulation of the H9C2 cells with ISP $(50 \mu \mathrm{M})$ led to significant ( $p$-value $<0.01)$ escalation in the mitochondrial membrane potential (MMP) (Figure 6C). This increase in MMP is well-correlated to the elevated generation of ROS in the H9C2 cells stimulated with ISP (Figure 6B,C). Co-treatment of the ISP $(50 \mu \mathrm{M})$-treated H9C2 cells with YDR significantly ( $p$-value $<0.01$ ) reduced the elevated level of MMP in a dose-dependent manner (Figure 6C).

Mitochondrial origin superoxide anions $\left(\mathrm{O}^{-2}\right)$ were detected intracellularly using a nitroblue tetrazolium assay. We observed a significant $(p$-value $<0.001)$ rise in the generation of intracellular $\mathrm{O}^{-2}$ in the H9C2 cells when treated with ISP $(50 \mu \mathrm{M})$ alone (Figure 6D). Concurrent treatment of the ISP-induced H9C2 cells with YDR significantly ( $p$-value $<0.01$ ) reduced the stimulated release of $\mathrm{O}^{-2}$ (Figure 6D). These results correlated well with the observed modulation of ISP-stimulated intracellular ROS generation by YDR in the H9C2 cells (Figure 6B,C). Hence, based on these results, we could validate that YDR efficiently reduced the oxidative stress-stimulating property of the ISP in the cardiomyocytes. 


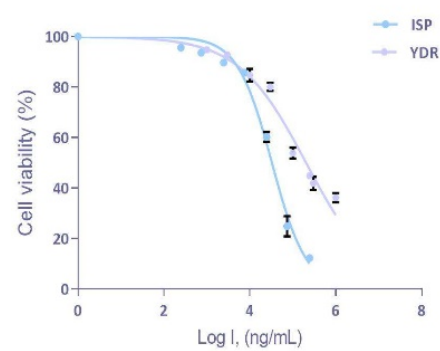

D

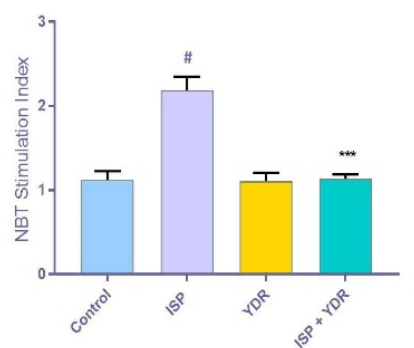

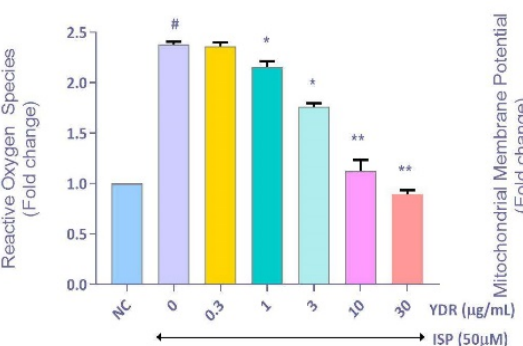

E

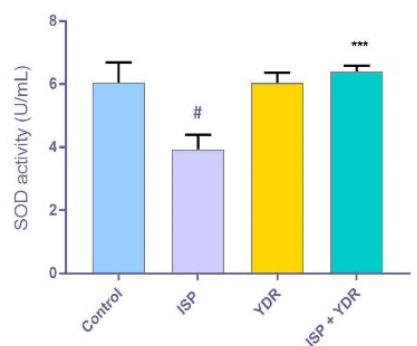

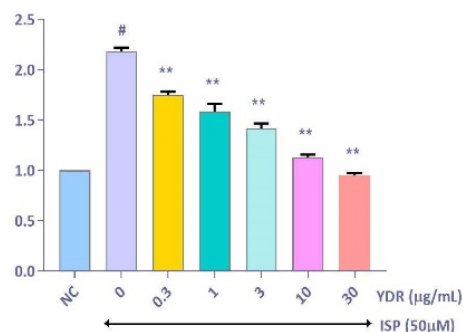

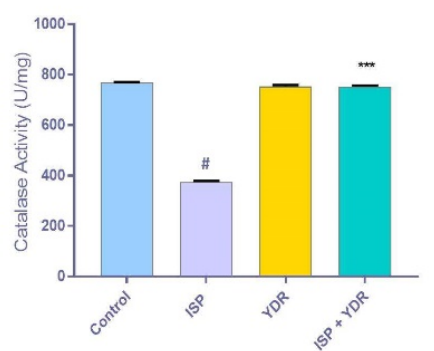

Figure 6. Dose screening and oxidative stress analysis in $\mathrm{H} 9 \mathrm{C} 2$ cells exposed to isoproterenol (ISP) and Yogendra Ras (YDR). (A) MTT-based dose screening in the H9C2 cells showed a dose-dependent loss of cell viability following exposure to the ISP $\left(\mathrm{IC}_{20}=50 \mu \mathrm{M}\right.$ and $\left.\mathrm{IC}_{50}=122.4 \mu \mathrm{M}\right)$ and YDR $\left(\mathrm{IC}_{20}=30 \mu \mathrm{g} / \mathrm{mL}\right.$ and $\left.\mathrm{IC}_{50}=205 \mu \mathrm{g} / \mathrm{mL}\right)$. (B) Stimulation of the H9C2 cells with ISP $(50 \mu \mathrm{M})$ induced up-regulation in the production of intracellular reactive oxygen species and its reduction following treatment with YDR. (C) Mitochondrial membrane potential (MMP) increment was detected in the ISP-stimulated H9C2 cells. It was reduced following co-treatment with YDR. (D) YDR also reduced the ISP-stimulated generation of superoxide ions $\left(\mathrm{O}^{-2}\right)$ in $\mathrm{H} 9 \mathrm{C} 2$ cardiomyocytes as indicated through the intracellular formation of formazan in the NBT assay. (E) Reduction in the generation of $\mathrm{O}^{-2}$ in the ISP-stimulated H9C2 cells following treatment with YDR was confirmed through the recovery in the intracellular levels of superoxide dismutase (SOD) enzyme. (F) Intracellular catalase enzyme levels were also recovered in the ISP-stimulated H9C2 cells following treatment with YDR. All the experiments were performed in biological and technical triplicates. Results represent mean \pm SD. The statistical analysis results were analyzed using one-way ANOVA followed by Dunnett's post-hoc test: $p$-value $\#<0.01$ (ISP alone versus normal control) and ${ }^{* *}<0.01,{ }^{* * *}<0.001$ (YDR co-treatment versus ISP alone).

\subsection{Anti-Oxidants Modulation by YDR in ISP-Induced H9C2 Cells}

Stimulation of the H9C2 cells with ISP $(50 \mu \mathrm{M})$ led to a significant ( $p$-value $<0.01)$ reduction in the levels of the anti-oxidants i.e., superoxide dismutase (SOD) and catalase, indicating onset of oxidative stress (Figure $6 \mathrm{E}, \mathrm{F})$. This was significantly ( $p$-value $<0.01$ ) recovered through the co-treatment of the ISP-stimulated H9C2 cells with YDR showing a recovery in the levels of both SOD and catalase. The SOD and catalase enzymatic assay result further correlated well with the previously observed high induction of $\mathrm{O}^{-2}$ and ROS in the $\mathrm{H} 9 \mathrm{C} 2$ cells when treated with ISP alone and its amelioration following a co-treatment with YDR (Figure 6B,D).

ROS generation is known to induce the expression of Cyclooxygenase (COX) and the subclass of NADPH oxidases (NOX), which further act as inflammatory mediators during the induction of cardiotoxicity. Therefore, we studied the oxidative stress-stimulated up-regulation of the mRNA expression profiles of pro-inflammatory mediators COX-2, NOX-2, and NOX-4 (Figure 7A-C). Both COX-2 and NOX-4 showed a significant ( $p$-value $<0.01$ ) fold increase following the induction of H9C2 cells with ISP $(50 \mu \mathrm{M})$, while the elevated levels of NOX-2 were not statistically significant. YDR alone did not induce any stimulated increase in the inflammatory mediators. In the present study, concurrent treatment of ISP-stimulated H9C2 cells with YDR $(30 \mu \mathrm{g} / \mathrm{mL})$ led to a $(p<0.05)$ reduction in 
the expression of COX-2 and NOX-4 (Figure 7A,C). The reduction was also observed in the case of NOX-2 but was not statistically significant when compared to the ISP-alone-stimulated H9C2 cells (Figure 7B). Thus, the results validated the observed antioxidant and anti-inflammatory properties of the YDR in ameliorating ISP-stimulated oxidative stress and inflammation in the cardiomyocytes through concurrent treatment.
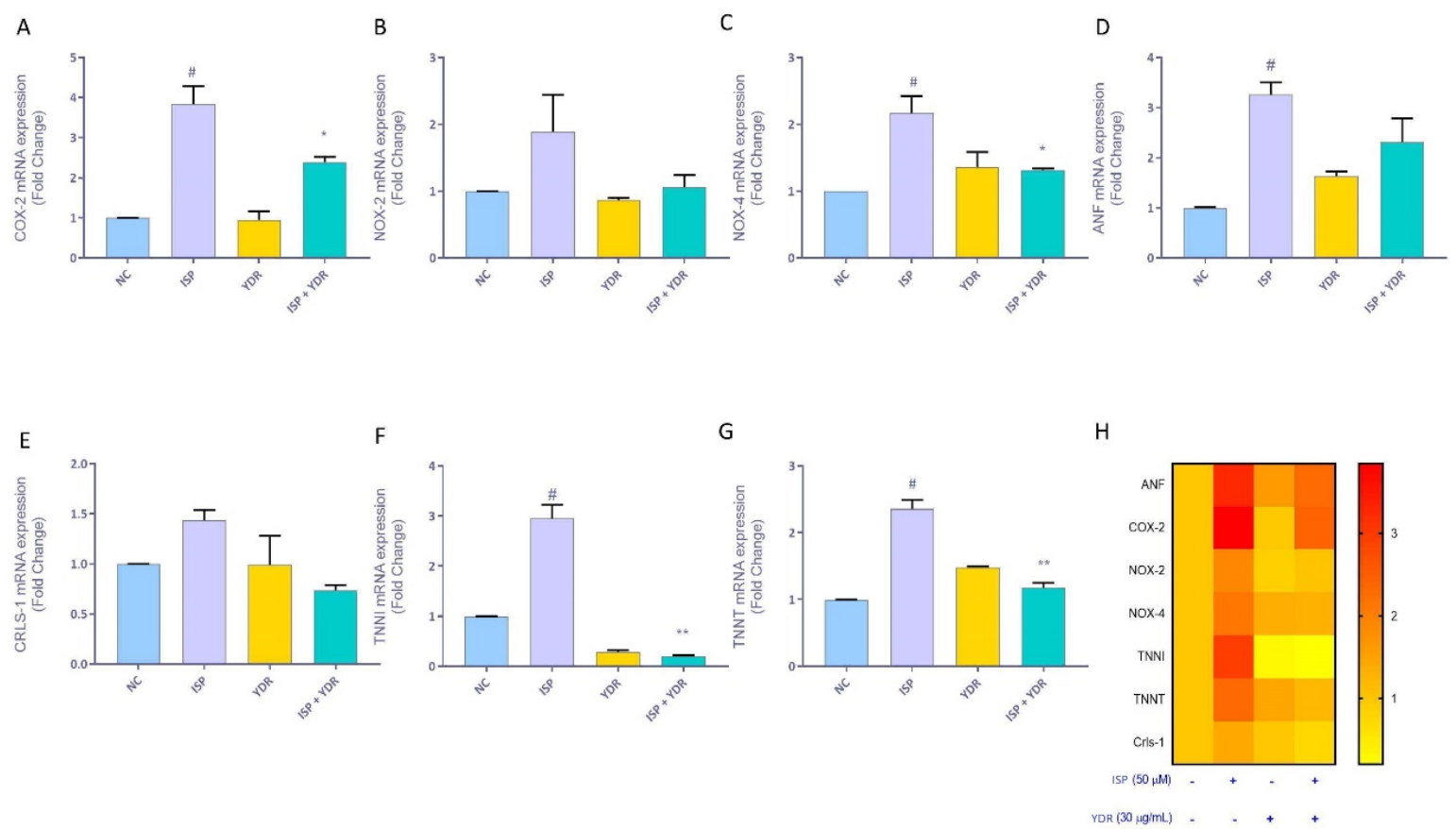

Figure 7. Down-regulation of cardiac-hypertrophy-associated non-clinical and clinical molecular biomarkers by Yogendra Ras (YDR) in the isoproterenol (ISP)-stimulated H9C2 cells. H9C2 cells stimulated with ISP showed an increase in the mRNA expression levels of the pro-inflammatory mediator genes: (A) Cyclooxygenase-2 (COX-2), (B) NADPH oxidase-2 (NOX-2). and (C) NADPH oxidase-4 (NOX-4) using quantitative real-time PCR. Significant down-regulation of these pro-inflammatory genes was observed following a co-treatment of the ISP-stimulated H9C2 cells with YDR. Treatment of the H9C2 cells with ISP also induced an up-regulation of the expression of the fetal cardiac fetal gene (D) atrial natriuretic factor (ANF) and (E) cardiolipin (CRLS-1), (F) troponin I (TNN-I), and (G) troponin $\mathrm{T}(\mathrm{TNN}-\mathrm{T})$. Expression of all the genes was normalized against the house-keeping gene $\beta$-actin. Co-treatment of the ISP-stimulated H9C2 cells with YDR significantly reduced the expression of all the up-regulated non-clinical and clinical genes. H) The heat map was generated to summarize the gene expression study. All the experiments were performed in biological and technical triplicates. Results represent mean $\pm \mathrm{SD}$. For the statistical analysis, results were analyzed using one-way ANOVA followed by Dunnett's post-hoc test: $p$-value \# $<0.01$ (ISP/YDR versus normal control) and * $<0.05$, ** $<0.01$ (YDR co-treatment versus ISP alone).

\subsection{Non-Clinical and Clinical Genetic Biomarker Modulation by YDR in ISP-Induced H9C2 Cells}

The onset of $\mathrm{CH}$ has been associated with the activation of the fetal cardiac remodeling genes. Following stimulation of the H9C2 cells with ISP, significant ( $p$-value $<0.01$ ) overexpression of fetal cardiac gene atrial natriuretic factor (ANF) was observed (Figure 7D). This overexpression of the ANF was down-regulated following a co-treatment of the ISP-treated H9C2 cells with YDR $(30 \mu \mathrm{g} / \mathrm{mL})$ (Figure 7D). Similarly, other essential clinical biomarker genes such as troponin I (TNN-I), troponin $\mathrm{T}$ (TNN-T), and cardiolipin (CRLS-1) were also found to be up-regulated in the ISP-stimulated $\mathrm{H} 9 \mathrm{C} 2$ cells as compared to normal controls. Overexpression of these clinical biomarker genes was significantly reduced in the ISP-treated $\mathrm{H} 9 \mathrm{C} 2$ cells following a concurrent treatment with YDR $(30 \mu \mathrm{g} / \mathrm{mL})$ (Figure 7E-G). Expression of the clinical and non-clinical biomarkers related to cardiac 
tissue remodeling, oxidative stress, and inflammatory responses and associated clinical biomarkers are summarized in the heat map in Figure 7H. Change in the color intensity clearly indicates that the YDR co-treatment in the ISP-stimulated H9C2 cells varyingly modulated the expression of the analyzed clinical and non-clinical CH biomarkers (Figure $7 \mathrm{H}$ ).

\section{Discussion}

Cardiovascular disease remains one of the most prominent causes of mortality throughout the world. Heart failure is defined as a deficiency of the heart's ability to adequately pump blood in response to systemic demands. YDR is a traditional Indian Ayurvedic formulation prepared using mercury $(\mathrm{Hg})$, gold $(\mathrm{Au})$, and tin $(\mathrm{Sn})$. Generally, YDR is used as a neurostimulator and acts as a catalyst with other Ayurvedic formulations to increase their therapeutic efficacy [35]. According to the compendium of classical Indian medicinal text, Ayurveda Sar Sangraha, YDR can also be prescribed for cardiac ailments [36].

Based on the physicochemical characterization, YDR was found to be heterogeneous in shape and size, containing large quantities of $\mathrm{Hg}, \mathrm{Sn}$, and $\mathrm{O}$. Complementing these findings, ICP-MS analysis of the YDR particles showed the presence of $\mathrm{Hg}(9.8 \%)$ and $\mathrm{Au}(7.9 \%)$. Interestingly, the absence of Au peak in the EDX and in the ICP-MS analysis might be due to the masking effect induced by the gold-palladium coating process of the samples. The detected elemental constituents of the YDR were close to those mentioned in the ancient Indian text of Bhaisajya Ratnāvalī [35]. Hence, our ICP-MS detections were well within the prescribed range for $\mathrm{Hg}$ and $\mathrm{Au}$. Dry powder XRD analysis showed the presence of $\mathrm{HgS}$, in the forms of Cinnabar and Metacinnabar, pure Au, iron (hematite), As-Fe alloy, and arsenic impurity $\left(\mathrm{As}_{4} \mathrm{O}_{6}\right)$. Mercury in the form of Cinnabar has been extensively used in traditional Indian and Chinese medicines in treating various diseases such as neuropathy and cardiac diseases $[37,38]$. Cinnabar has been shown to have low GI tract absorption as compared to mercuric chloride $\left(\mathrm{HgCl}_{2}\right)$ and demonstrates $1000 \times$ lower toxicity as compared to methyl mercury [37]. Other compounds such as hematite and pure Au have also been reported to not be toxic to humans in low doses. Hydrodynamic diameter analysis of the YDR particles using the dynamic light scattering technique showed that in the presence of biomolecules present in cell culture media with $2 \%$ FBS, their relative size distribution reduced significantly. This change in size distribution of the YDR particles was due to the formation of a bio-corona surrounding, modifying their relative surface attributes.

In the present study, we applied erythromycin as an inducer of $\mathrm{CH}$ in the D. rerio as earlier studies have shown that this can induce $\mathrm{CH}$ [8]. Since $D$. rerio contains a two-chambered heart, directing the hypertrophy toward the left ventricle is not possible. In the present study, based on the ECG reading development of $\mathrm{CH}$ was observed through an increase in the amplitudes of the QRS wave. Furthermore, analysis of the Cornell product, Cornell voltage, Sokolow-Lyon, and Romhilt-Estes point criteria obtained from the ECG readout clearly showed the induction of $\mathrm{CH}$ [28]. Induction of $\mathrm{CH}$ was also visually confirmed through the histological analysis of the whole fish heart and septum wall thickness. Treatment of the ERY-stimulated fish with YDR or verapamil clearly showed an amelioration of the ERY-induced $\mathrm{CH}$ in the fish heart. Earlier studies using zebrafish have shown similar efficacy with the synthetic standard-of-care drug verapamil [39,40]. Elevated CRP and platelet aggregation levels have been associated with an increase in cardiovascular function failures in hypertensive adults [33,41]. Treatment of the CH-induced $D$. rerio with YDR significantly reduced the stimulated release of CRP and platelet aggregation, indicating a reduction in the level of $\mathrm{CH}$. Our results confirmed the earlier ECG and oxidative stress-related findings and showed that the YDR has equal potential in ameliorating drug-induced $\mathrm{CH}$. Therefore, this is the first study to report the efficacy of metal-based ancient Ayurvedic medicine in modulating $\mathrm{CH}$.

Based on the in-vivo study results, we expected YDR to play a major role in cardioprotection, by reducing stress signaling, and cardiac remodeling. In our in-vitro studies, we applied isoproterenol (ISP) for the induction of hypertrophy. ISP helps in normalizing the diminished heartbeat. However, prolonged use of ISP could also lead to change in the left and right ventricular wall function and 
physiology inducing cardiomyopathy [42]. Therefore, in our present study, we employed ISP for inducing $\mathrm{CH}$ in the rat cardiomyocyte $(\mathrm{H} 9 \mathrm{C} 2)$ cell lines, through the process of oxidative stress-induced damage. Applying a sub-toxic inhibitory $20 \%\left(\mathrm{IC}_{20}\right)$ concentration of ISP in the $\mathrm{H} 9 \mathrm{C} 2$ cells, we further studied the efficacy of YDR. ISP induced loss of cell viability, redox imbalance, and up-regulation in the mRNA expression of non-clinical and clinical biomarkers of $\mathrm{CH}$. YDR given to the H9C2 cells in combination with the ISP ameliorated these drug-induced $\mathrm{CH}$ biomarkers.

Oxidative stress-induced redox imbalance in the cardiomyocytes is one of the primary reasons for the development of myocyte hypertrophy [43]. Mitochondria are responsible for the generation of $~ 95 \%$ of ATP required by the heart for functioning, cellular signaling, controlled cell death, and generation of ROS such as superoxide anions and hydrogen peroxide [44]. Hence, prolonged cardiac oxidative stress and development of $\mathrm{CH}$ is directly associated with mitochondrial dysfunction and the generation of oxidative stress. In our study, we observed that ISP induced an increase in mitochondrial membrane potential along with $\mathrm{ROS}$ and $\mathrm{O}^{-2}$ generation. Potential growth in the ROS generation leading to a reduction in the cardiac mitochondrial cytochrome $\mathrm{c}$ and ubiquinone levels further modulating the mitochondrial membrane potential has been well-documented [45,46]. H9C2 cells with a co-treatment of the ISP and YDR showed a significant reduction in oxidative stress through the reduced release of both intracellular ROS and $\mathrm{O}^{-2}$. Hence, YDR acted as an anti-oxidant, or as a stimulator for cellular anti-oxidant (catalase and superoxide dismutase) levels. Both these antioxidants were significantly reduced through the treatment of $\mathrm{H} 9 \mathrm{C} 2$ cells with ISP alone and enhanced through a co-treatment with YDR.

Cyclooxygenases (COX) and nicotinamide adenine dinucleotide phosphate oxidases (NADPH oxidases/NOX) represent the primary group of enzymes involved in the generation of ROS. Overexpression of COX-2 has been associated with angiotensin-II induced oxidative stress signaling pathways and $\mathrm{CH}$ [47]. In the present study, co-exposure of the H9C2 cells with YDR and ISP led to an inhibition in the over-expression of COX-2 mRNA triggered by ISP alone. Both these biomarkers indicated that they inhibited the induction of $\mathrm{CH}$ in the $\mathrm{H} 9 \mathrm{C} 2$ cells possibly through the inhibition of the AT1R pathway. As a part of the mitochondrial enzymatic system, NOX acts as the main source for the production of $\mathrm{O}^{-2}$ in cardiomyocytes [48]. NOX plays an important role in the pathogenesis of cardiac remodeling [49]. A steady overexpression of NOX-2 and NOX-4 were depicted in heart failure patients, and the deletion of NOX-4 was observed to inhibit $80 \%$ development of $\mathrm{CH}$ in rats [48]. In our mRNA expression study, YDR was found to significantly down-regulate the over-expression of NOX-2 and NOX-4 in the cardiomyocytes induced by ISP, single-handedly. The study suggested a significant role for the YDR to act as an antioxidant inhibiting the ISP-induced oxidation and hypertrophy.

Oxidative stress activates the cell-death-associated cascades and contributes to maladaptive myocardial remodeling. The induction of hypertrophy in the adult myocardium is associated with the partial recapitulation of the embryonic program observed during cardiac development. Atrial natriuretic factor (ANF) is associated with remodeling during the induction of $\mathrm{CH}$. It is a very sensitive marker, and overexpression of ANF in adult heart can lead to the development of defects in the chamber myocardium of the atria, ventricles, atrioventricular canal, and pacemaker tissue patients [49]. In our study, we found that the YDR co-treatment with ISP reduced the mRNA over-expression of the ANF induced by ISP alone, indicating a reduction in hypertrophy conditions. Other molecular sources for measuring the $\mathrm{CH}$ inhibitory efficacy of YDR were clinical biomarkers, troponin I (TNN-I), troponin $\mathrm{T}$ (TNN-T), and cardiolipin (CRLS-1). Cardiac troponin I and T are subunits of the cardiac actin-myosin complex, and their release into the systemic circulation represents myocardial injuries and necrosis [50]. Cardiolipin (CRLS-1) is a phospholipid found only in the inner mitochondrial membrane and plays an important role in the formation of mitochondrial cristae and super-complexes in the electron transport chain and bioenergetics. Hence, any mitochondrial dysfunction in the cardiomyocytes is represented by cardiolipin release in circulation. In our study, we observed an increase in the mRNA expression level of TNN-I, TNN-T, and CRLS-1, by ISP induction. An increase in these levels confirmed the oxidative damage induced by the ISP and the onset of cardiomyocyte hypertrophy. YDR co-treatment 
led to a significant reduction in the mRNA expression levels of these three genes, indicating a reduction in cellular oxidative damage and inhibition of $\mathrm{CH}$. Hence, the mRNA expression analysis validated the cellular and biochemical parameters observed for the antioxidant behavior of the YDR in modulating ISP-induced redox imbalance and cardiac hypertrophy. Results from the study indicate a noteworthy role of the YDR in modulating $\mathrm{CH}$. Future studies would be directed towards understanding the intracellular role of metals associated with YDR in modulating cardiac hypertrophy; and exploring the possibility of clinical trials with YDR in patients with cardiac hypertrophy.

\section{Conclusions}

In conclusion, zebrafish represent an effective model for the study of cardiac hypertrophy and its amelioration by traditional Indian medicine Yogendra Ras (YDR). YDR was found to be formed mainly of cinnabar, gold, and tin. In the ERY-stimulated D. rerio $\mathrm{CH}$ model, YDR acted as a therapeutic medicine and helped in the normalization of cardiac parameters, represented by ECG, heart morphology, and septum wall thickness. YDR also ameliorated ERY-stimulated release of pro-inflammatory C-reactive protein and normalized platelet aggregation time. In the in-vitro model of ISP-stimulated H9C2 cells, YDR was found to act as an anti-oxidant agent, helping in the reduction of excessive intracellular reactive oxygen species and superoxide anions generation and an associated increase in mitochondrial membrane potential. YDR also reduced the ISP-stimulated changes in the levels of antioxidant enzymes and, at molecular levels, clinical and non-clinical biomarkers associated with $\mathrm{CH}$. Taken together, the results suggest a role for YDR as an alternative therapeutic medicine for the treatment of oxidative stress and inflammation-associated cardiac ailments such as cardiac hypertrophy.

Author Contributions: Conceptualization, A.B.; Data curation, K.B.; Formal analysis, K.B.; Funding acquisition, A.B. and A.V.; Investigation, Y.R. and K.B.; Methodology, Y.R., K.B. and A.V.; Project administration, A.V.; Resources, A.B. and A.V.; Supervision, A.B. and A.V.; Validation, Y.R. and K.B.; Visualization, K.B.; Writing-original draft, K.B.; Writing-review \& editing, A.B. and A.V. All authors have read and agreed to the published version of the manuscript.

Funding: This research work was funded by Patanjali Research Foundation Trust, Haridwar, India.

Acknowledgments: We are indebted to Param Shradhey Swami Ramdev Ji for his institutional and financial supports to accomplish this research project. We appreciate our CRO partners, Pentagrit Research, Chennai, India for their zebrafish test facilities and experimentation; and Eurofins and Analytical Services, Bengaluru, India for ICP-MS analysis. We extend our gratitude to Dr. L.P. Singh and colleagues at Central Building Research Institute, Roorkee, India for their support with the Scanning Electron Microscope, Electron Dispersive X-Ray, and XRD analysis; and Professor Partha Roy and colleagues, Indian Institute of Technology, Roorkee, India for support with particle size analysis. We acknowledge the ayurvedic literature supports from Dr. Rajesh Mishra for classical text search and shloka transliterations. We would also extend our gratitude to Ms. Priyanka Kandpal, Mr. Brij Kishore, Mr. Pradeep Nain, Mr. Tarun Rajput, Mr. Gagan Kumar, and Mr. Lalit Mohan for their swift administrative supports.

Conflicts of Interest: The authors declare that this research was conducted in the absence of any other commercial or financial relationships that could be construed as a potential conflict of interest.

\section{References}

1. Bournele, D.; Beis, D. Zebrafish models of cardiovascular disease. Heart Fail. Rev. 2016, 21, 803-813. [CrossRef] [PubMed]

2. Liu, C.C.; Li, L.; Lam, Y.W.; Siu, C.W.; Cheng, S.H. Improvement of surface ECG recording in adult zebrafish reveals that the value of this model exceeds our expectation. Sci. Rep. 2016, 6, 25073. [CrossRef] [PubMed]

3. Vornanen, M.; Hassinen, M. Zebrafish heart as a model for human cardiac electrophysiology. Channels (Austin) 2016, 10, 101-110. [CrossRef] [PubMed]

4. Nakamura, M.; Sadoshima, J. Mechanisms of physiological and pathological cardiac hypertrophy. Nat. Rev. Cardiol. 2018, 15, 387-407. [CrossRef]

5. Heineke, J.; Molkentin, J.D. Regulation of cardiac hypertrophy by intracellular signalling pathways. Nat. Rev. Mol. Cell Biol. 2006, 7, 589-600. [CrossRef] 
6. Berenji, K.; Drazner, M.H.; Rothermel, B.A.; Hill, J.A. Does load-induced ventricular hypertrophy progress to systolic heart failure? Am. J. Physiol. Heart Circ. Physiol. 2005, 289, H8-H16. [CrossRef]

7. Ray, W.A.; Murray, K.T.; Meredith, S.; Narasimhulu, S.S.; Hall, K.; Stein, C.M. Oral erythromycin and the risk of sudden death from cardiac causes. N. Engl. J. Med. 2004, 351, 1089-1096. [CrossRef]

8. Gunalan, B.; Joseph, B.; Jyothi, S.; Sundar, R.; Sangeetha, S.; Kar, B. Isolation and preliminary screen of bioactive fractions from different microbial isolates towards construction of a microbial drug bank. Int J. Drug Des. Dis. 2012, 3, 753-756.

9. Behr, E.R.; Roden, D. Drug-induced arrhythmia: Pharmacogenomic prescribing? Eur. Heart J. 2013, 34, 89-95. [CrossRef]

10. Nagano, M.; Higaki, J.; Nakamura, F.; Higashimori, K.; Nagano, N.; Mikami, H.; Ogihara, T. Role of cardiac angiotensin II in isoproterenol-induced left ventricular hypertrophy. Hypertension 1992, 19, 708-712. [CrossRef]

11. Najafi, A.; Sequeira, V.; Kuster, D.W.; van der Velden, J. Beta-adrenergic receptor signalling and its functional consequences in the diseased heart. Eur. J. Clin. Investig. 2016, 46, 362-374. [CrossRef] [PubMed]

12. Rosca, M.G.; Tandler, B.; Hoppel, C.L. Mitochondria in cardiac hypertrophy and heart failure. J. Mol. Cell Cardiol 2013, 55, 31-41. [CrossRef] [PubMed]

13. Muntean, D.M.; Sturza, A.; Danila, M.D.; Borza, C.; Duicu, O.M.; Mornos, C. The Role of Mitochondrial Reactive Oxygen Species in Cardiovascular Injury and Protective Strategies. Oxid Med. Cell Longev 2016, 2016, 8254942. [CrossRef] [PubMed]

14. Balkrishna, A.; Ranjan, R.; Sakat, S.S.; Sharma, V.K.; Shukla, R.; Joshi, K.; Devkar, R.; Sharma, N.; Saklani, S.; Pathak, P.; et al. Evaluation of polyherbal ayurvedic formulation 'Peedantak Vati' for anti-inflammatory and analgesic properties. J. Ethnopharmacol 2019, 235, 361-374. [CrossRef]

15. Balkrishna, A.; Sakat, S.S.; Joshi, K.; Joshi, K.; Sharma, V.; Ranjan, R.; Bhattacharya, K.; Varshney, A. Cytokines Driven Anti-Inflammatory and Anti-Psoriasis Like Efficacies of Nutraceutical Sea Buckthorn (Hippophae rhamnoides) Oil. Front. Pharm. 2019, 10, 1186. [CrossRef]

16. Balkrishna, A.; Sakat, S.S.; Joshi, K.; Paudel, S.; Joshi, D.; Joshi, K.; Ranjan, R.; Gupta, A.; Bhattacharya, K.; Varshney, A. Herbo-mineral formulation 'Ashwashila' attenuates rheumatoid arthritis symptoms in collagen-antibody-induced arthritis (CAIA) mice model. Sci. Rep. 2019, 9, 8025. [CrossRef]

17. Balkrishna, A.; Sakat, S.S.; Joshi, K.; Paudel, S.; Joshi, D.; Joshi, K.; Ranjan, R.; Gupta, A.; Bhattacharya, K.; Varshney, A. Anti-Inflammatory and Anti-Arthritic Efficacies of an Indian Traditional Herbo-Mineral Medicine "Divya Amvatari Ras" in Collagen Antibody-Induced Arthritis (CAIA) Mouse Model Through Modulation of IL-6/IL-1beta/TNF-alpha/NFkappaB Signaling. Front. Pharm. 2019, 10, 659. [CrossRef]

18. Sen, G.D. Bhaisajya Ratnavali, 43th ed.; Mishra, S., Ed.; Chaukhamba Surbharati Prakashan: Varanasi, India, 2013.

19. Bhisgacharya, G.P.G. Vatavyadhi Chikitsa; Nirmal Ayurveda Sansthan: Aligarh, India, 1984.

20. EPA. International Actions for Reducing Mercury Emissions and Use, Environmental Protection Agency, 2015. Environmental Protection Agency, United States. Available online: http://www2.epa.gov/internationalcooperation/international-actions-reducing-mercury-emissions-and-use (accessed on 6 April 2020).

21. Pharmacopeia_Comittee. Pharmacopoeia of China; Chemical Industry Press: Beijing, China, 2005.

22. Kilkenny, C.; Browne, W.J.; Cuthill, I.C.; Emerson, M.; Altman, D.G. Improving bioscience research reporting: The ARRIVE guidelines for reporting animal research. PLoS Biol. 2010, 8, e1000412. [CrossRef]

23. Ducharme, N.A.; Reif, D.M.; Gustafsson, J.A.; Bondesson, M. Comparison of toxicity values across zebrafish early life stages and mammalian studies: Implications for chemical testing. Reprod. Toxicol. 2015, 55, 3-10. [CrossRef]

24. Shin, J.W.; Seol, I.C. Interpretation of animal dose and human equivalent dose for drug development. J. Korean Orient Med. 2010, 31, 1-7.

25. Wang, L.W.; Huttner, I.G.; Santiago, C.F.; Kesteven, S.H.; Yu, Z.Y.; Feneley, M.P.; Fatkin, D. Standardized echocardiographic assessment of cardiac function in normal adult zebrafish and heart disease models. Dis. Model. Mech. 2017, 10, 63-76. [CrossRef] [PubMed]

26. DePasquale, C.; Leri, J. The influence of exercise on anxiety-like behavior in zebrafish (Danio rerio). Behav. Process. 2018, 157, 638-644. [CrossRef]

27. Zhao, Y.; Yun, M.; Nguyen, S.A.; Tran, M.; Nguyen, T.P. In Vivo Surface Electrocardiography for Adult Zebrafish. J. Vis. Exp. 2019. [CrossRef] [PubMed] 
28. Morrison, I.; Clark, E.; Macfarlane, P.W. Evaluation of the electrocardiographic criteria for left ventricular hypertrophy. Anadolu Kardiyol Derg 2007, 7 (Suppl. 1), 159-163. [PubMed]

29. Choi, H.S.; Kim, J.W.; Cha, Y.N.; Kim, C. A quantitative nitroblue tetrazolium assay for determining intracellular superoxide anion production in phagocytic cells. J. Immunoass. Immunochem 2006, 27, 31-44. [CrossRef]

30. Weydert, C.J.; Cullen, J.J. Measurement of superoxide dismutase, catalase and glutathione peroxidase in cultured cells and tissue. Nat. Protoc 2010, 5, 51-66. [CrossRef]

31. Beauchamp, C.; Fridovich, I. Superoxide dismutase: Improved assays and an assay applicable to acrylamide gels. Anal. Biochem. 1971, 44, 276-287. [CrossRef]

32. Yacoub, M.; Brand, T.; Schlueter, J. Think small: The zebrafish as a novel disease model in QCRC. Qatar Found. Annu. Res. Forum Proc. 2012. [CrossRef]

33. Assadi, F. C-reactive protein and incident left ventricular hypertrophy in essential hypertension. Pediatr Cardiol 2007, 28, 280-285. [CrossRef]

34. Riazanov, A.S.; Gabbasov, Z.A.; Iurenev, A.P. Platelet aggregation in patients with various forms of left ventricular hypertrophy and its changes at long-term follow-up and treatment. Ter Arkh 2000, 72, 50-54.

35. Tripathi, S.P. Bhaisajratnawali; Tej Kumar Press: Lucknow, India, 1987; Volume 3.

36. Ayurveda Sar Sangrah, 18th ed.; Shri Baidyanath Ayurveda Bhawan Ltd.: Allahabad, India, 2009.

37. Liu, J.; Shi, J.Z.; Yu, L.M.; Goyer, R.A.; Waalkes, M.P. Mercury in traditional medicines: Is cinnabar toxicologically similar to common mercurials? Exp. Biol Med. (Maywood) 2008, 233, 810-817. [CrossRef] [PubMed]

38. Efferth, T.; Li, P.C.; Konkimalla, V.S.; Kaina, B. From traditional Chinese medicine to rational cancer therapy. Trends Mol. Med. 2007, 13, 353-361. [CrossRef] [PubMed]

39. Dhillon, S.S.; Doro, E.; Magyary, I.; Egginton, S.; Sik, A.; Muller, F. Optimisation of embryonic and larval ECG measurement in zebrafish for quantifying the effect of QT prolonging drugs. PLoS ONE 2013, 8, e60552. [CrossRef] [PubMed]

40. Muntean, B.S.; Horvat, C.M.; Behler, J.H.; Aboualaiwi, W.A.; Nauli, A.M.; Williams, F.E.; Nauli, S.M. A Comparative Study of Embedded and Anesthetized Zebrafish in vivo on Myocardiac Calcium Oscillation and Heart Muscle Contraction. Front. Pharm. 2010, 1, 139. [CrossRef]

41. Gabbasov, Z.; Parfyonova, Y.; Popov, E.; Gavrilov, I.; Anuchin, V.; Dubov, P.; Djakonova, Y. Association of platelet function in hypertensive patients with left ventricular hypertrophy, transient myocardial ischemia, and coronary artery disease. Platelets 1998, 9, 191-195. [CrossRef]

42. Oomen, A.; Semsarian, C.; Puranik, R.; Sy, R.W. Diagnosis of Arrhythmogenic Right Ventricular Cardiomyopathy: Progress and Pitfalls. Heart Lung Circ. 2018, 27, 1310-1317. [CrossRef]

43. Panth, N.; Paudel, K.R.; Parajuli, K. Reactive Oxygen Species: A Key Hallmark of Cardiovascular Disease. Adv. Med. 2016, 2016, 9152732. [CrossRef]

44. Facundo, H.; Brainard, R.E.; Caldas, F.R.L.; Lucas, A.M.B. Mitochondria and Cardiac Hypertrophy. Adv. Exp. Med. Biol 2017, 982, 203-226. [CrossRef]

45. Osterholt, M.; Nguyen, T.D.; Schwarzer, M.; Doenst, T. Alterations in mitochondrial function in cardiac hypertrophy and heart failure. Heart Fail. Rev. 2013, 18, 645-656. [CrossRef]

46. Siasos, G.; Tsigkou, V.; Kosmopoulos, M.; Theodosiadis, D.; Simantiris, S.; Tagkou, N.M.; Tsimpiktsioglou, A.; Stampouloglou, P.K.; Oikonomou, E.; Mourouzis, K.; et al. Mitochondria and cardiovascular diseases-from pathophysiology to treatment. Ann. Transl Med. 2018, 6, 256. [CrossRef]

47. Pialoux, V.; Poulin, M.J.; Hemmelgarn, B.R.; Muruve, D.A.; Chirico, E.N.; Faes, C.; Sola, D.Y.; Ahmed, S.B. Cyclooxygenase-2 Inhibition Limits Angiotensin II-Induced DNA Oxidation and Protein Nitration in Humans. Front. Physiol 2017, 8, 138. [CrossRef] [PubMed]

48. Zhao, Q.D.; Viswanadhapalli, S.; Williams, P.; Shi, Q.; Tan, C.; Yi, X.; Bhandari, B.; Abboud, H.E. NADPH oxidase 4 induces cardiac fibrosis and hypertrophy through activating Akt/mTOR and NFkappaB signaling pathways. Circulation 2015, 131, 643-655. [CrossRef] [PubMed] 
49. Sergeeva, I.A.; Christoffels, V.M. Regulation of expression of atrial and brain natriuretic peptide, biomarkers for heart development and disease. Biochim Biophys Acta 2013, 1832, 2403-2413. [CrossRef] [PubMed]

50. Jaffe, A.S.; Ravkilde, J.; Roberts, R.; Naslund, U.; Apple, F.S.; Galvani, M.; Katus, H. It's time for a change to a troponin standard. Circulation 2000, 102, 1216-1220. [CrossRef] [PubMed]

(C) 2020 by the authors. Licensee MDPI, Basel, Switzerland. This article is an open access article distributed under the terms and conditions of the Creative Commons Attribution (CC BY) license (http://creativecommons.org/licenses/by/4.0/). 